\title{
Foam-Metal Liner Attenuation of Low-Speed Fan Noise
}

\author{
Daniel L. Sutliff ${ }^{1}$ \\ NASA Glenn Research Center, Cleveland, OH 44135, USA \\ and \\ Michael G. Jones ${ }^{2}$ \\ NASA Langley Research Center Research, Hampton, VA, 23681, USA
}

\begin{abstract}
A foam-metal liner for attenuation of fan noise was developed for and tested on a low speed fan. This type of liner represents a significant advance over traditional liners due to the possibility for placement in close proximity to the rotor. An advantage of placing treatment in this region is the modification of the acoustic near field, thereby inhibiting noise generation mechanisms. This can result in higher attenuation levels than can be achieved by liners located in the nacelle inlet. In addition, foam-metal liners could potentially replace the fan rub-strip and containment components, ultimately reducing engine components and thus weight, which can result in a systematic increase in noise reduction and engine performance. Foam-metal liners have the potential to reduce fan noise by $4 \mathrm{~dB}$ based on this study.
\end{abstract}

\section{Nomenclature}

$\zeta=$ characteristic impedance

$\mathrm{BPF} \quad=$ blade passing frequency

$=$ propagation constant

$=$ depth

$\mathrm{RPMc}=$ corrected revolutions per minute (fan speed)

$=$ air density

FML = foam-metal liner

$=$ speed of sound

OTR = over-the-rotor

$=$ Mach Number

SDOF = single degree of freedom

psi $\quad=$ pounds-per-square-inch

\section{Introduction}

ignificant reduction in aircraft noise is required to meet ongoing noise regulation in the USA and Europe. Since $\checkmark$ the turbofan engine is a large contributor to aircraft noise, any overall reduction in aircraft noise must address engine noise reduction ${ }^{1}$. A typical method is to attenuate the noise in the turbofan duct using acoustic liners. Standard liners with Single-Degree-of-Freedom (SDOF) perforate-over-honeycomb design are typically tuned to maximize attenuation of the blade passage frequency. These liners have traditionally been installed in the inlet or exhaust nacelle, a relatively benign environment. It is desirable to install liners closer to the rotor, or even over the rotor, which is a much harsher pressure and temperature environment. If designed correctly, liners placed in this region can provide a pressure release surface, thereby reducing the farfield noise emitted by the engine by more than can be achieved via attenuations due to conventional liner mechanisms. Foam-metal (Figure 1) has the potential to survive in this environment. A liner made of foam-metal and placed over the rotor has the potential to provide significant attenuation of fan noise.

This paper documents the acoustic attenuation characteristics of a foam-metal liner (FML) installed in a low-speed fan model. Foam-metal intrinsic acoustic properties measured via impedance tube tests are presented. Noise reduction potential of a FML at standard inlet and over-the-rotor (OTR) locations were investigated. Flow data are presented, but due to the nature of the test rig, detailed effects on the fan performance parameters such as thrust and efficiency are not available.

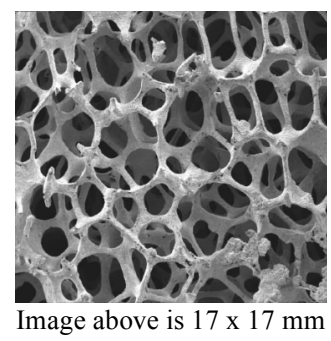

Image above is $17 \times 17 \mathrm{~mm}$
Desirable Foam-metal

Characteristics:

excellent acoustic absorption high temperature capability high impact resistance resistance to fluid absorption

Figure 1. Close-up of FoamMetal (60ppi, $8 \%$ density).

\footnotetext{
${ }^{1}$ Aerospace Engineer, Acoustics Branch, MS 54-3, AIAA Senior Member.

2 Aerospace Engineer, Structural Acoustics Branch, MS 463, AIAA Associate Fellow.
} 


\section{Impedance Tube Testing}

\section{A. Test Samples}

Foam-metal constructed from a cobalt alloy (see Figure 2) was selected for this study because of the uniformity of its acoustic properties (i.e., constant acoustic properties throughout the material). Samples with porosities of 20 to 100 pores per inch and densities (i.e., percentage of sample volume consisting of the cobalt alloy) of 6 to $8 \%$ were tested in the NASA Langley normal incidence tube, and the Two-Thickness Method ${ }^{2}$ was used to determine the intrinsic properties of each foam type. The following sections describe the test methods used to determine the intrinsic properties of these materials and evaluate the spectral properties.

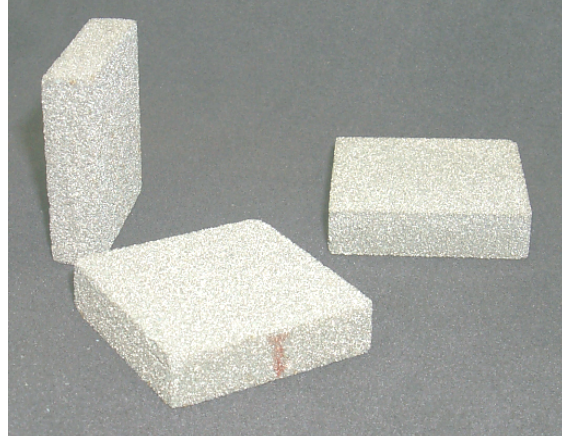

Figure 2. Photograph of Foam-metal Samples (2" $x$ 2" x 0.425")

\section{B. Test Procedures}

The experimental evaluation was conducted in three steps. First, the Two-Microphone Method ${ }^{3,4}$ was used to measure the normal incidence acoustic impedance of two samples, comprised of two and four 0.425 "-thick layers (the only thicknesses available) of foam-metal, respectively. Next, the Two-Thickness Method was used to educe intrinsic acoustic properties from these component measurements. Finally, the Two-Microphone Method was used to measure the normal incidence acoustic impedance of a third sample, comprised of three 0.425 "-thick layers of foam, and the measured impedance spectra was compared with the corresponding impedance spectra predicted from these intrinsic acoustic properties.

\section{Two-Microphone Method}

The Two-Microphone Method was used with the NASA Langley normal incidence tube (Figure 3) to determine the surface impedance of each sample. These data were generated with a random noise acoustic source, at overall sound pressure levels (OASPL, integrated over frequency range of 500 to $3000 \mathrm{~Hz}$ ) of 120 and $140 \mathrm{~dB}$, as measured by the reference microphone flush-mounted 0.25 " from the surface of the sample. Data were acquired at frequencies from 500 to $3000 \mathrm{~Hz}$, in increments of $25 \mathrm{~Hz}$. In total, eight tests were conducted for this investigation (two source levels, four samples). As expected, results acquired with each sample were observed to be independent of the source OASPL. This result demonstrates the linearity of the material. Foam material is generally observed to be linear; i.e., the surface impedance is independent of source OASPL. This was also observed to be true for the foams considered in this study. Thus, for the sake of brevity, only the results for an OASPL of $140 \mathrm{~dB}$ are presented in this report.

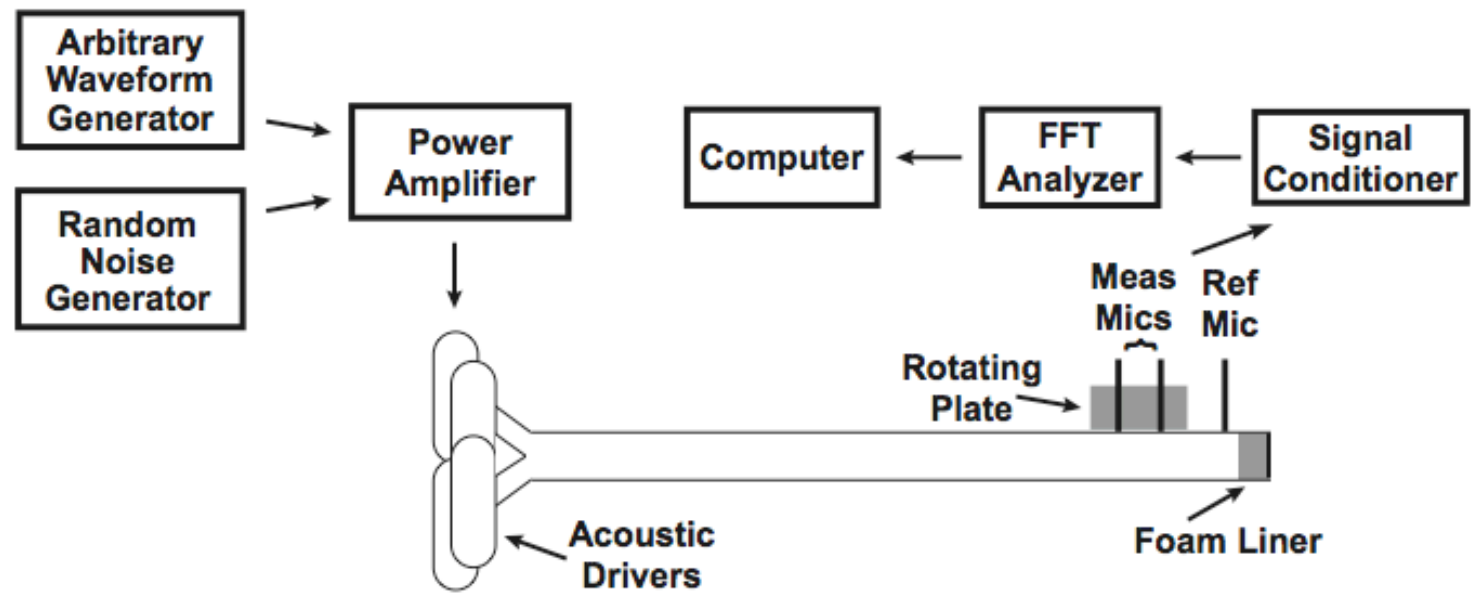

Figure 3. Sketch of NASA Langley Normal Incidence Tube with Supporting Instrumentation. 


\section{Two-Thickness Method}

The Two-Thickness Method is well established for educing the intrinsic properties (characteristic impedance, $\zeta_{c}$, and propagation constant, $\Gamma$ ) of bulk absorbing structures. The core of this method is the solution of the following two equations:

$$
\begin{aligned}
& \zeta_{1}=\zeta_{c} \operatorname{coth}\left(\Gamma d_{1}\right) \\
& \zeta_{2}=\zeta_{c} \operatorname{coth}\left(\Gamma d_{2}\right)
\end{aligned}
$$

where $\zeta_{1}$ and $\zeta_{2}$ represent two measured surface impedances on two separate test samples of depths $d_{1}$ and $d_{2}$, taken from what is assumed to be a homogeneous, continuous structure. In the current study, the analysis is greatly simplified by selecting sample depths such that $d_{2}=2 d_{1}$. Specifically, surface impedance spectra, $\zeta_{1}$ and $\zeta_{2}$, measured with 0.85 and 1.70 "-thick samples (two and four layers of foam-metal), respectively, were used as input for the Two-Thickness Method. Based on these measured impedance spectra, the characteristic impedance and propagation constant spectra of this type of foam-metal can be determined as follows:

$$
\begin{gathered}
\xi_{c}=\sqrt{\zeta_{1}\left(2 \xi_{2}-\zeta_{1}\right)} \\
\Gamma=\Gamma_{r}+I \Gamma_{i}=\frac{1}{2 d_{1}} \log \left(\frac{1+a}{1-a}\right) \\
a=\sqrt{\frac{2 \zeta_{2}-\zeta_{1}}{\zeta_{1}}}
\end{gathered}
$$

From these two complex quantities, the attenuation rate and phase rate can be determined. The attenuation rate $\left(\Gamma_{\mathrm{r}}\right)$ is the rate at which the amplitude of the acoustic wave decays as it travels through the sample. Correspondingly, the phase rate $\left(\Gamma_{\mathrm{i}}\right)$ is the rate at which the phase of the acoustic wave varies as it travels through the sample. If the parent material of the two initial samples is sufficiently uniform, such that the intrinsic properties of the material can be successfully educed from these two samples, the impedance $\xi_{s}$ of a third sample with thickness $d_{s}(1.265$ " for this study) can then be determined using

$$
\zeta_{s}=\zeta_{c} \operatorname{coth}\left(\Gamma d_{s}\right)
$$

A comparison between the measured impedance of the third sample and the impedance predicted using the $\zeta_{c}$ and $\Gamma$ educed using the Two-Thickness Method can be used to assess the "validity" of the educed parameters. The L2-Norm, L2, is used for this evaluation. It is computed as follows:

$$
L 2=\frac{1}{N} \sqrt{\sum_{i=1}^{N}\left|\zeta_{m, i}-\zeta_{p, i}\right|^{2}}
$$

where $\zeta_{m, i}$ and $\zeta_{p, i}$ are the measured and predicted impedances, respectively, at the $i^{\text {th }}$ frequency, and $N$ is the total number of frequencies used in the evaluation. Ideally, the value of $L 2$ should be zero, indicating exact comparison between the measured and predicted impedances for samples with depths that are different from those used as input to the method. Thus, any departure from zero is (1) a measure of experimental error, or (2) a breakdown of the continuum assumption (e.g., material imperfections).

\section{Results}

The measured impedance spectra for 0.85 " and 1.70 "-thick samples (two and four layers of foam-metal) are provided in Figure 4. As described earlier, these impedance spectra were used as input to the Two-Thickness Method. Equations 3-5 were then used to compute the corresponding characteristic impedance and propagation constant for this foam-metal. These intrinsic acoustic properties were then used to predict the acoustic impedance spectrum for the 1.245"-thick sample. A comparison of the predicted and measured acoustic impedance spectra is provided in Figure 5. The comparison is exceptional, indicating the intrinsic properties of the foam-metal have been successfully educed. The L2-Norm, L2, computed from the comparison of the predicted and measured acoustic 
impedance spectra for this sample has a value of 0.002 . For the frequencies used in this study ( $25 \mathrm{~Hz}$ increments from $400 \mathrm{~Hz}$ to $3000 \mathrm{~Hz}$ ), this corresponds to an average error between the measured and predicted resistances and reactances (real and imaginary components of acoustic impedance) of $0.015 \rho c$ ( $\rho c$ is the characteristic impedance of air). This extremely small error provides confidence in the ability of the model to predict the normal incidence acoustic impedance spectra that would be measured for any sample thickness within reasonable proximity to those included in the current study.

These impedances were then used to predict the absorption coefficient spectra for 1", 2" and 3"-thick samples of this foam type (Figure 6). Based on these results, the 80 pores per inch, $8 \%$ density cobalt alloy was deemed suitable for further detailed evaluation.

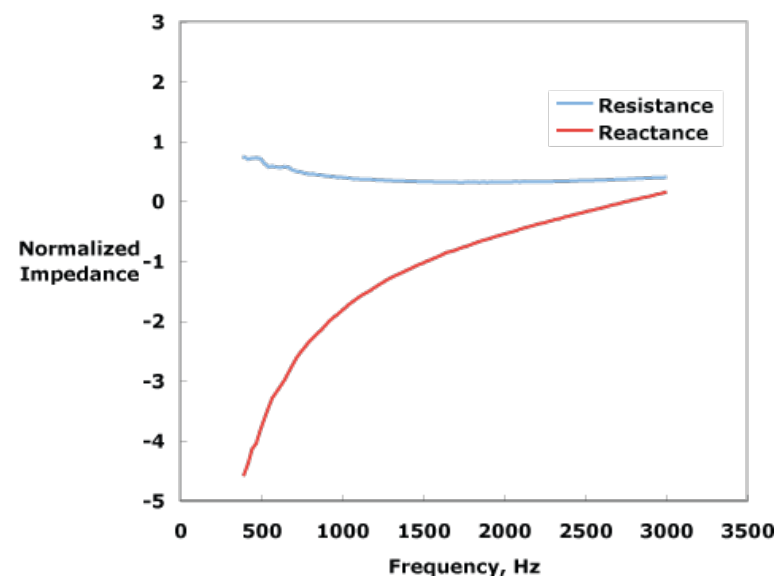

(a) 0.85 "-thick

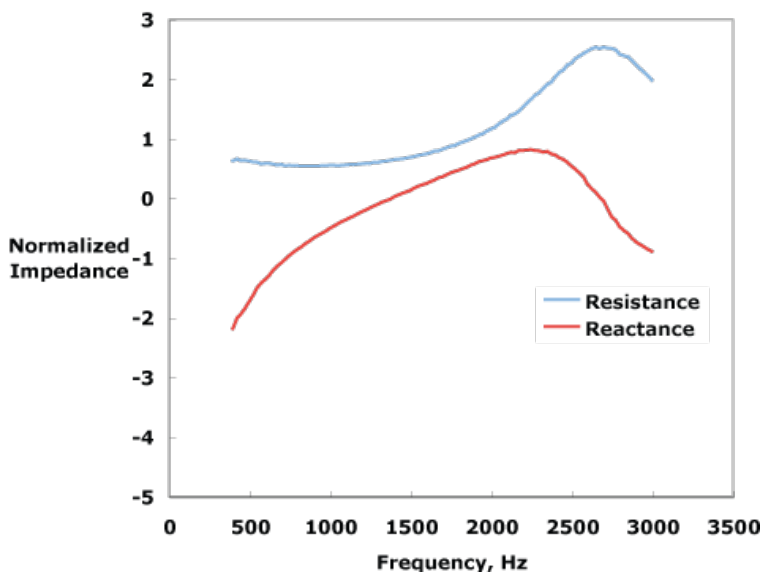

(b) 1.70"-thick

Figure 4. Normal Incidence Acoustic Impedance Foam-Metal Samples.

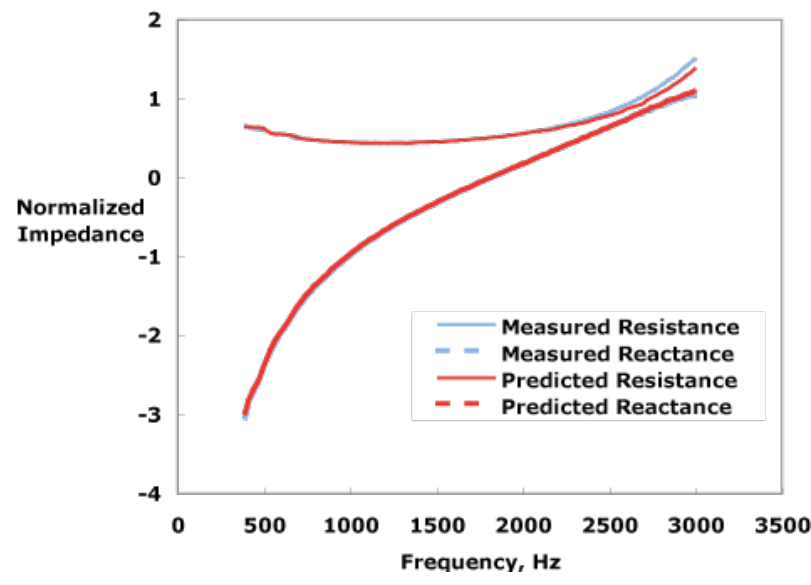

Figure 5. Comparison of Predicted and Measured Acoustic Impedance Spectra for 1.275"-thick Sample.

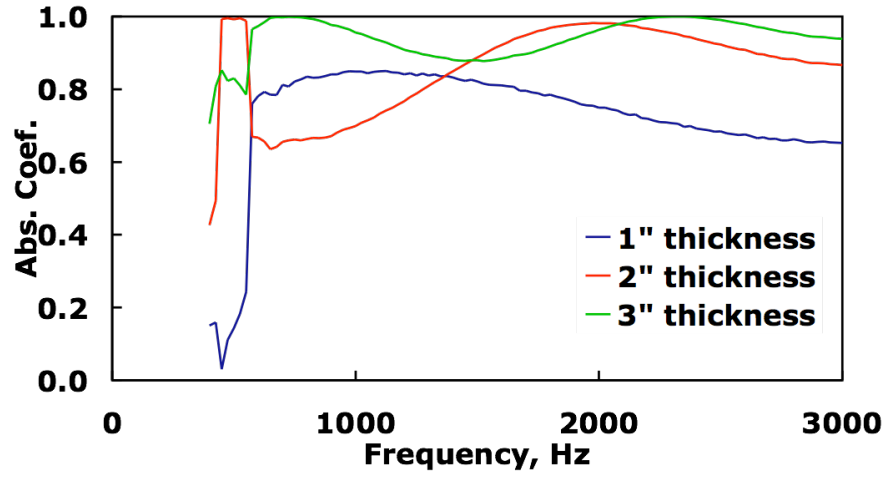

Figure 6. Absorption Coefficient Spectra for Three Thickness of 80 ppi, $8 \%$ density Foam-Metal. 


\section{Low-Speed Fan Testing}

\section{A. ANCF Test Bed}

The test bed was the Advanced Noise Control Fan ${ }^{5}$ (ANCF), a 4-foot diameter low speed fan used for validation of noise reductions concepts. The ANCF is a highly configurable, ducted fan rig located in the Aero-Acoustic Propulsion Laboratory ${ }^{6}$ (AAPL) at the NASA Glenn Research Center. The ANCF, shown in Figure 7, operates inside an enclosed, compact farfield arena designed such that the ANCF is in an anechoic environment within the AAPL. The AAPL is a hemispherical anechoic (to $125 \mathrm{~Hz}$.) test facility that allows for farfield noise measurements. An exterior view of the 65-foot high dome is shown in Figure 8. The ANCF exhausts out the open door.

The nominal operating condition of the ANCF is $1800 \mathrm{RPM}$ (375ft/sec tip speed) providing an inlet duct Mach number of $\sim 0.15$ and a fundamental blade passing frequency (BPF) of $\sim 500 \mathrm{~Hz}$. The ANCF is comprised of a series of 11 " or 12 " long cylindrical spools that are axially interchangeable, enabling rapid testing of a variety of configurations.

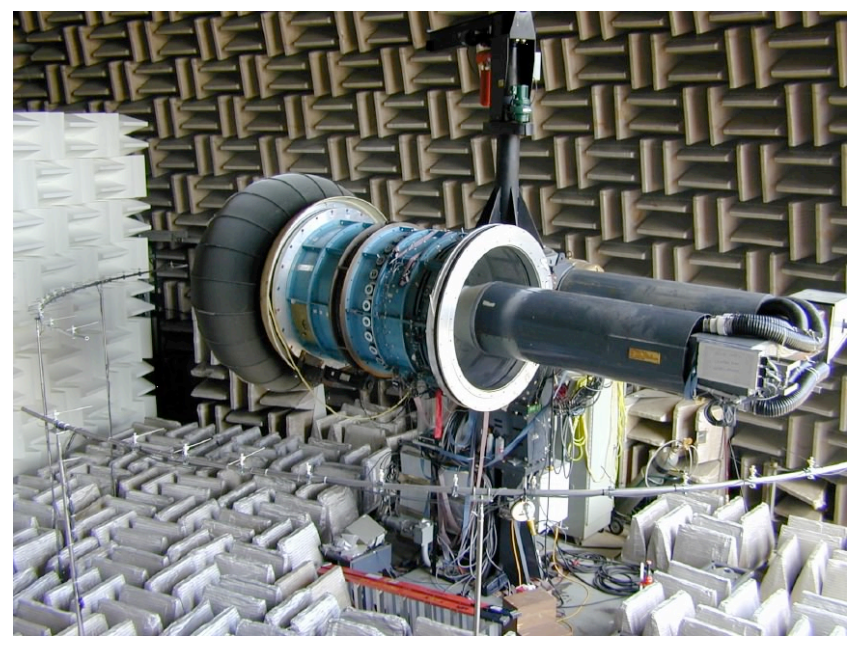

Figure 7. Advanced Noise Control Fan.

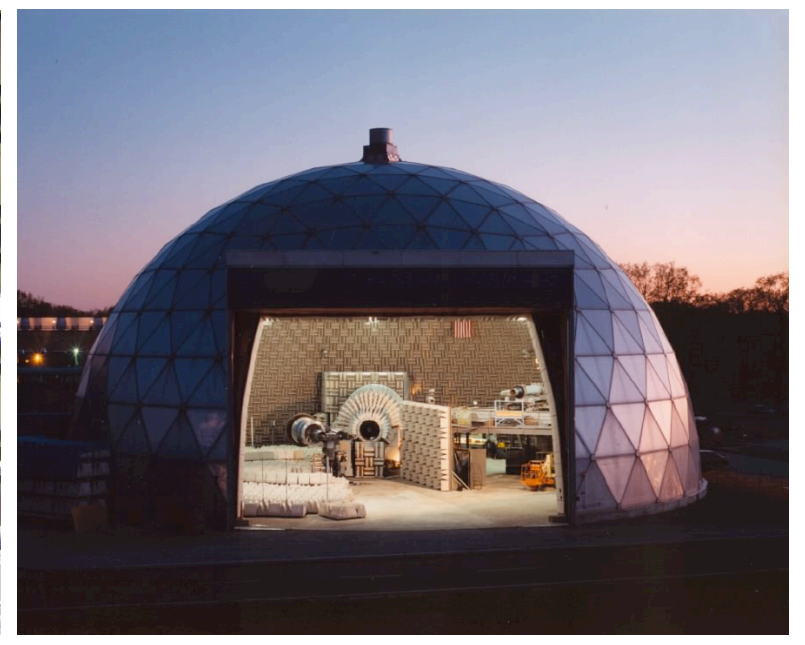

Figure 8. Aero-Acoustic Propulsion Laboratory.

\section{B. Test Hardware}

Based on the impedance tube test results of the foam metal samples and the known acoustic characteristics of the ANCF, a 9" long axial liner, having a total depth of 2", and with foam-metal characteristics of 80 ppi and $8 \%$ density was integrated into a 12" spool piece. The FML was manufactured in segments: two, 1-inch layers; each consisting of $\mathrm{a}^{1} / 8$ th circumferential arc. Figure 9 shows top and side view schematics of the FML design. Figure 10 shows the FML spool piece during model build-up and Figure 11 shows the FML installed in the OTR position.

The foam-metal liner was tested in several locations in the duct. The schematics of the configurations tested are presented in Figure 12. Two traditional inlet locations (Figure 12a), in addition to the OTR configuration (Figure $12 \mathrm{~b}$ ), and an over-the-stator (OTS - Figure 12c) configuration were tested. When the FML spool was installed over the rotor, it was situated so that the projected rotor path was approximately centered over the exposed liner material. The OTR configurations were tested without stator vanes installed (rotor only) so as to isolate the source. The other liner configurations tested had 14 stator vanes installed behind the rotor.

Hardwall configurations, and SDOF liners designed for an earlier program ${ }^{7,8}$, were used as comparative baselines. Results achieved with the current foam metal liner were compared with those previously measured with two standard SDOF liners. The normalized design resistances for these liners were 1.7 and 1.0 (impedance components normalized by $\rho c$ ), respectively. The liner core depths were 0.85 and 1.0 inches, resulting in resonance frequencies of 3221 and $2872 \mathrm{~Hz}$, respectively. The high-resistance liner was installed in the inlet, and the lowresistance liner (annular set) was installed in the exhaust (Figure 12d). 


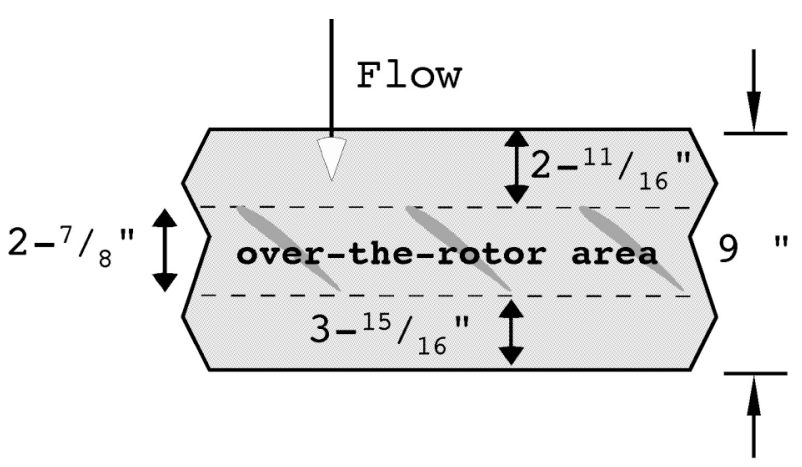

a. Top View

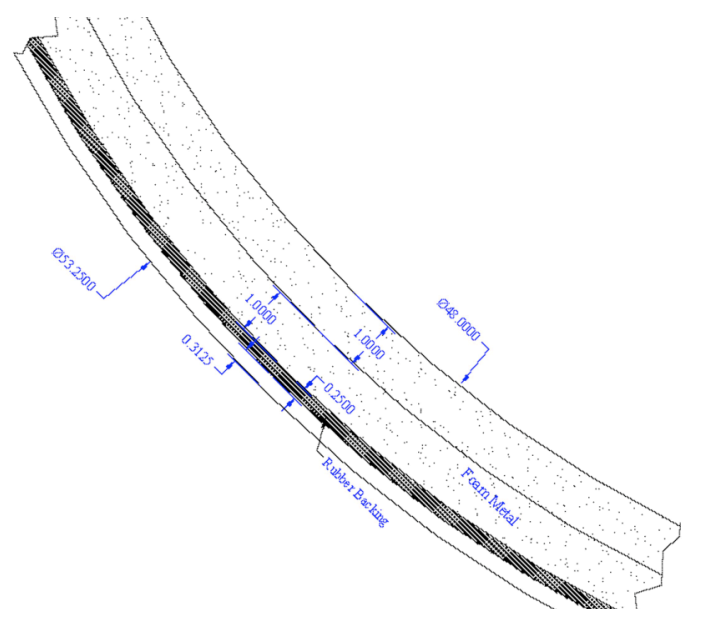

b. Side View

Figure 9. FML Schematics

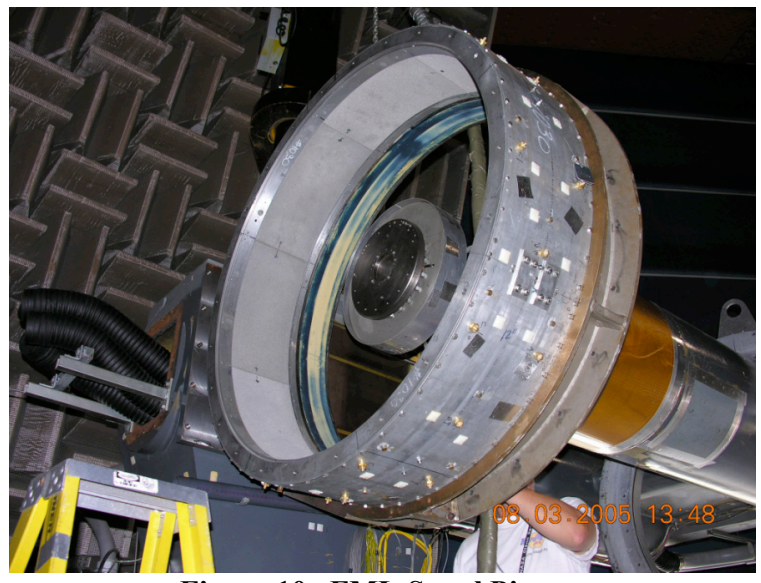

Figure 10. FML Spool Piece.

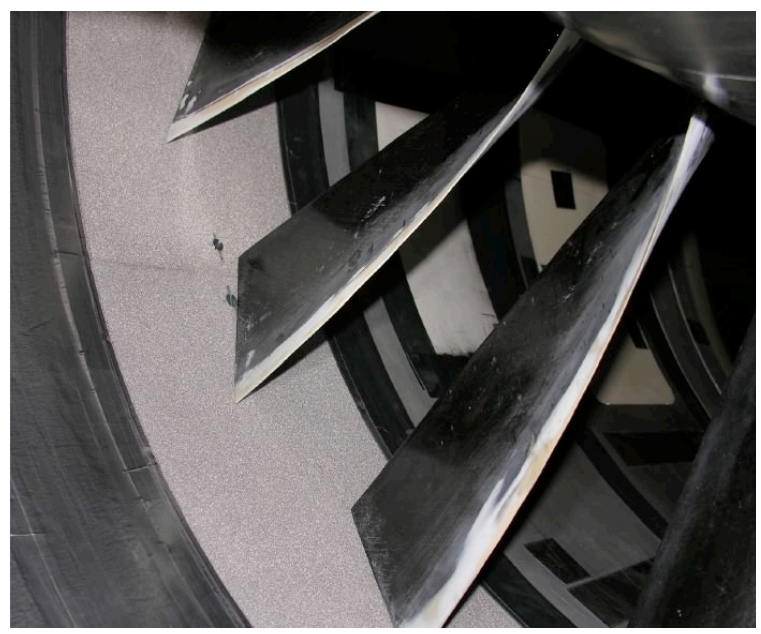

Figure 11. FML Spool Installed over Rotor.

Liner Configurations tested:

(a) FML in 2 inlet locations

(b) FML Over-the-Rotor (1" \& 2" depth)

(c) SDOF liner in inlet $\&$ exhaust ducts

(d) FML Over-the-Stator

Unique hardwall baseline created by taping over liner(s) in each configuration.
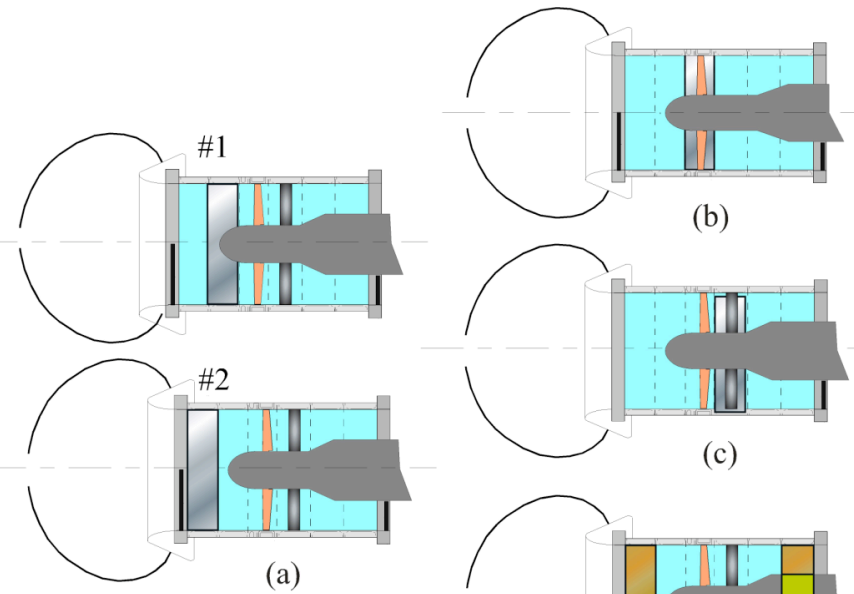

(b)

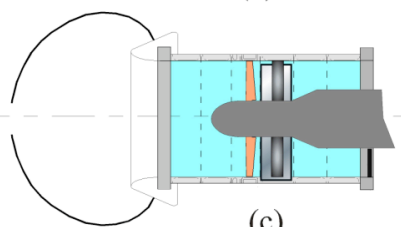

(c)

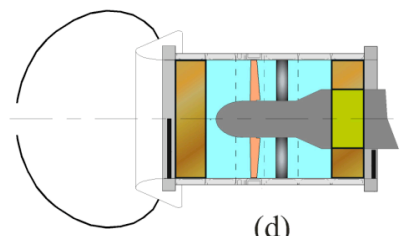

Figure 12. Schematic of Liner Configurations Tested on ANCF.

(d) 


\section{Results}

Farfield acoustic directivity, total and static pressure behind the rotor, steady state and dynamic wall pressures, and 2-component hot-film data were acquired. Table I indicates the data acquired for each configuration. Table II shows the corrected RPM at which each type of data were acquired.

Table I: Data Types Acquired.

\begin{tabular}{|c|c|c|c|c|c|}
\hline Tip Gap & Type of Data & Hardwall & $\begin{array}{c}\text { OTR } \\
\text { Softwall -1 }\end{array}$ & $\begin{array}{c}\text { OTR } \\
\text { Softwall - 2” }\end{array}$ & Inlet/OTS \\
\hline \multirow{3}{*}{ 3/32nd } & Farfield acoustic & Yes & Yes & Yes & Yes \\
& Unsteady/steady wall pressures & Yes & No & Yes & No \\
& Dynamic/static pressure traverses & Yes & No & Yes & No \\
& Hotfilm traverses & Yes & No & Yes & No \\
\hline \multirow{3}{*}{$\mathbf{1 / 3 2 n d}$} & Farfield acoustic & Yes & Yes & No & Yes \\
& Unsteady/steady wall pressures & Yes & Yes & No & No \\
& Dynamic/static pressure traverses & Yes & Yes & No & No \\
& Hotfilm traverses & Yes & Yes & No & No \\
\hline
\end{tabular}

Table II: Data Acquired.

\begin{tabular}{|c|c|}
\hline Type & Corr RPM \\
\hline $\begin{array}{c}\text { Farfield acoustic } \\
\text { Unsteady/steady wall pressures }\end{array}$ & $1800,1600,1400$ \\
\hline $\begin{array}{c}\text { Dynamic/static pressure traverses } \\
\text { Hotfilm traverses }\end{array}$ & 1800 \\
\hline
\end{tabular}

Farfield acoustic directivities were acquired using 30 microphones placed at a 12 -foot radius from the duct centerline. Fifteen of these were in an arc centered about the inlet exit plane $\left(0^{\circ}-90^{\circ}\right.$ measured from the inlet axis) and 15 were centered about the exhaust exit plane $\left(90^{\circ}-135^{\circ}\right.$ with $180^{\circ}$ being the exhaust axis). The spectra of each time history are processed in order to analyze the broadband content by removing the tones generated by the fan (shaft orders and harmonics) and integrating about a fan harmonic. This can be done exactly since the data are acquired synchronously to the shaft rotation. For example the $1^{\text {st }}$ harmonic band is defined as the integration from $0.5 \mathrm{~B}$ to $1.5 \mathrm{~B}$, the $2^{\text {nd }}$ harmonic band from $1.5 \mathrm{~B}$ to $2.5 \mathrm{~B}$, etc. $\mathrm{B}$ is the number of blades, so the $1^{\text {st }}$ harmonic band centered on 16 shaft orders and is the integration from 8 to 24 shaft orders. (Figure 13.) The data can then be converted to power by squaring the pressure and multiplying by the appropriate area, then normalizing by specific acoustic impedance (PWL). All acoustic data presented in this paper are broadband as defined by this process.

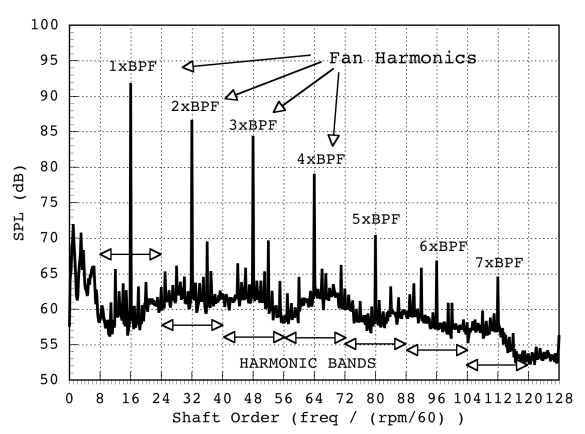

(a) Original Spectral Sample

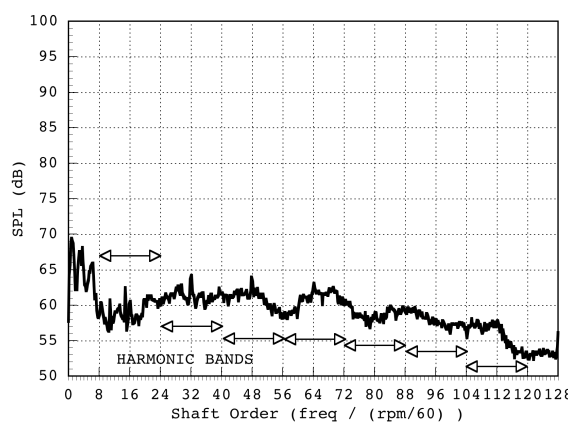

(b) Spectral Sample with Fan Harmonics Removed

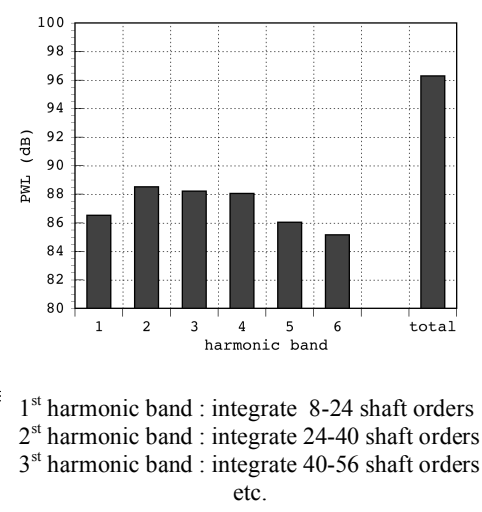

(c) Harmonic Bands

Figure 13. Example of Farfield Data Reduction into Harmonic Bands. 


\section{Acoustic Data}

Data were first acquired with the FML installed in the inlet duct. Two configurations were tested: Position 1, with the spool piece closest to the fan; and Position 2, where the spool piece was closest to the inlet lip (refer to Figure 12a). Broadband spectra from two representative microphones, one from the forward arc and one from the aft arc, are presented in Figure 14, comparing spectra from the inlet FML configurations to those obtained with a hardwall configuration. A clear acoustic attenuation from shaft order 16 (BPF) to 48 of up to $3 \mathrm{~dB}$ is seen at the forward arc microphone (Figure 14a). Note that with the liner in the inlet, no change in the aft-radiated spectra is seen (Figure14b).

The directivity of the broadband radiated noise from these inlet configurations is shown in Figure 15. The attenuation in the forward arc $\left(0^{\circ}-90^{\circ}\right)$ is seen most notably in the $2^{\text {nd }}$ through $4^{\text {th }}$ harmonic bands (Figure $15 \mathrm{~b}-\mathrm{d}$ ). Slightly greater attenuation with the FML in Position 2 can be seen in these harmonic bands. The attenuation in the higher harmonic bands (Figure 15e-f) is very modest. The radiated levels in the aft arc $\left(90^{\circ}-165^{\circ}\right)$ do not change significantly in the $1^{\text {st }}$ through $5^{\text {th }}$ harmonic bands. A small increase is noted in the $6^{\text {th }}$ harmonic band. It is speculated that this is due to increased turbulence from the higher surface roughness of the FML being ingested by the rotor.

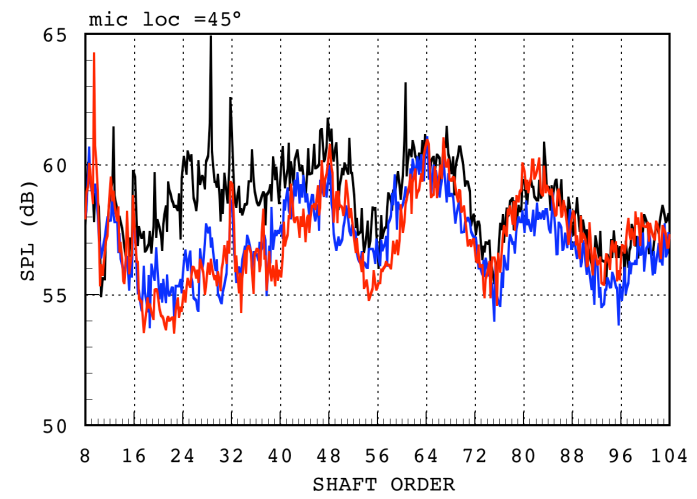

(a) Spectra from mic $\left(45^{\circ}\right.$

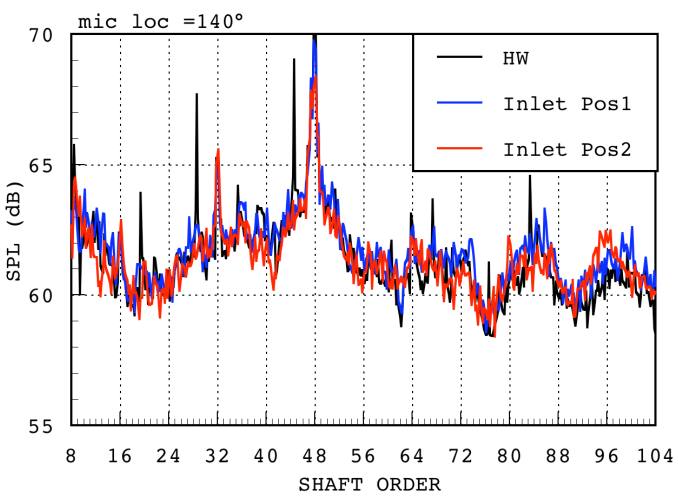

(b) Spectra from mic @ $140^{\circ}$

Figure 14. Representative Spectra of FML in Two Inlet Locations Compared to Hardwall.

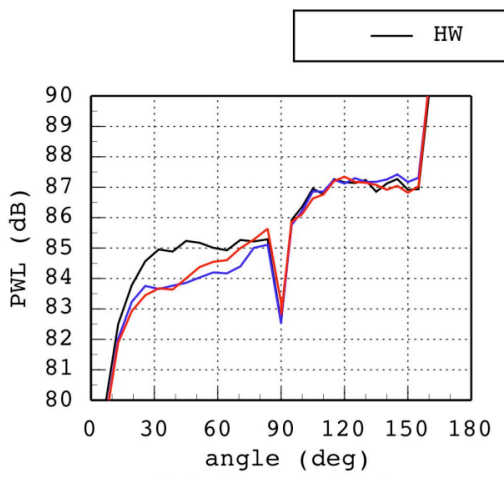

(a) 1st harmonic band

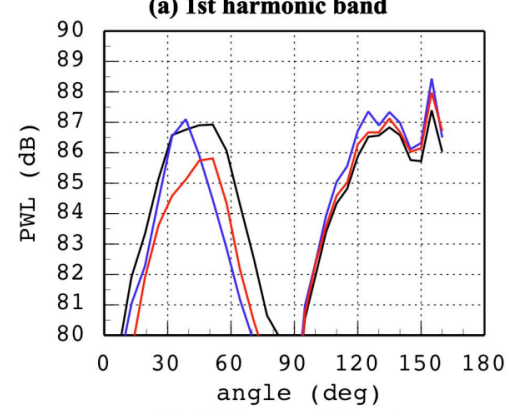

(d) 4th harmonic band

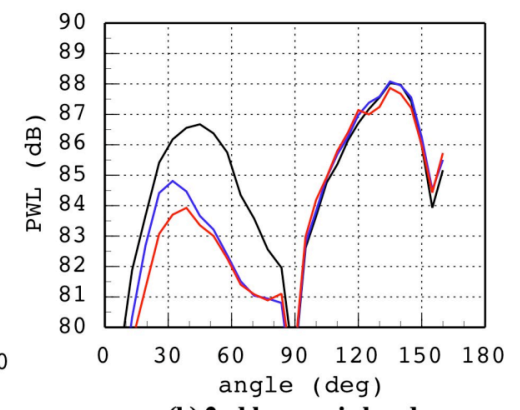

(b) 2nd harmonic band

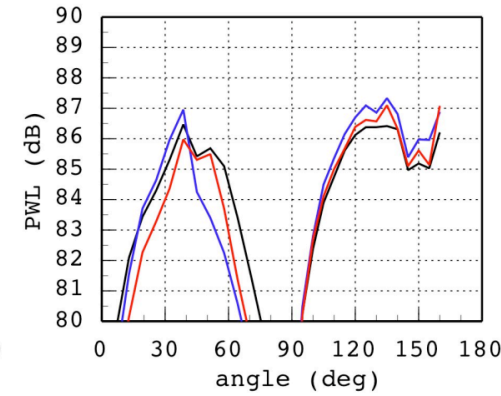

(e) 5th harmonic band
- Inlet Pos2

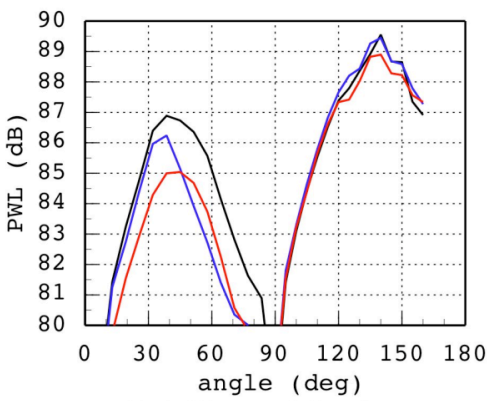

(c) 3rd harmonic band

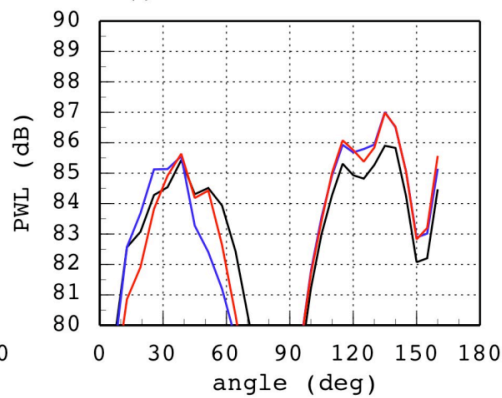

(f) 6th harmonic band

Figure 15. Farfield Directivity of FML in Inlet Compared to Hardwall. 
The spectral character of the FML installed over-the-rotor compared to the hardwall is shown in Figure 16; the broadband directivity for these configurations is shown in Figure 17. (As the ANCF is re-arranged to create this configuration, a new hardwall configuration is created by using hardwall tape to cover the liner, and then tested.) Significantly greater attenuation (compared to the inlet positions), up to $5 \mathrm{~dB}$, over the shaft order range above 16 (BPF) is measured in both the forward and aft farfield arcs. This is due to the anticipated synergistic benefit of having the treatment in close proximity to the source. It is not clear from the farfield acoustic data if this is a result of increased acoustic attenuation from the rotor-source, or due to a modification of the source itself (possibly from aerodynamic effects in the fan tip region), or a combination of effects.

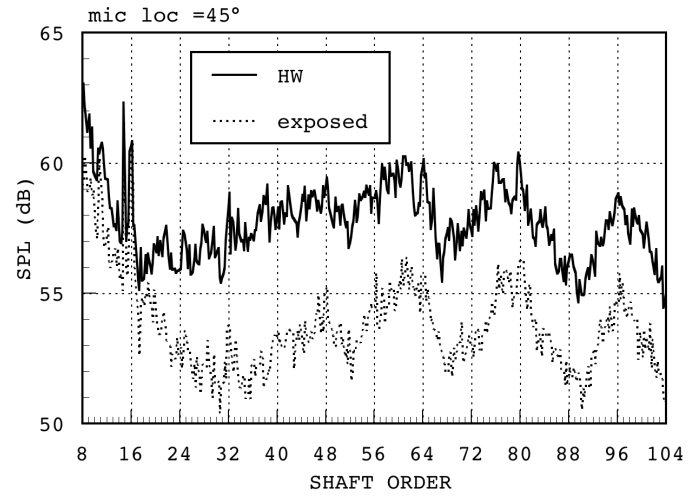

(a) Spectra from mic @ $45^{\circ}$

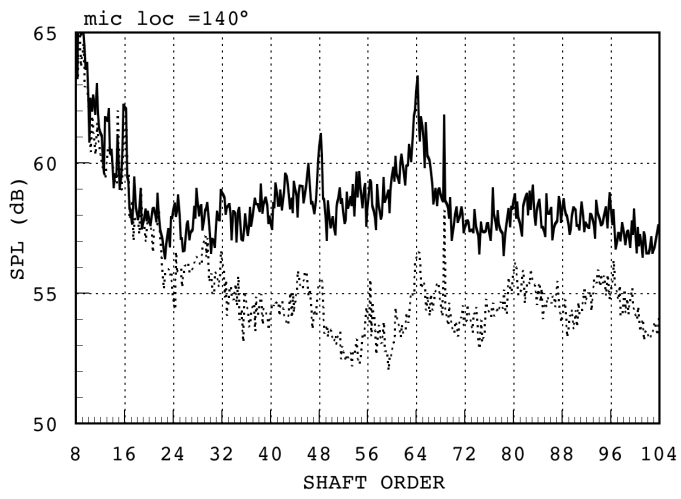

(b) Spectra from mic $@ 120^{\circ}$

Figure 16. Representative Spectra of FML Over-the-Rotor Compared to Hardwall.

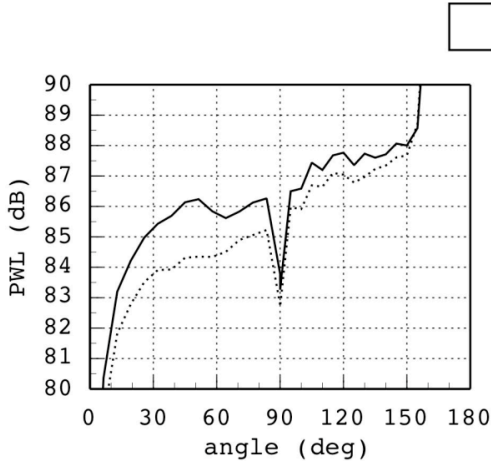

(a) 1st harmonic band

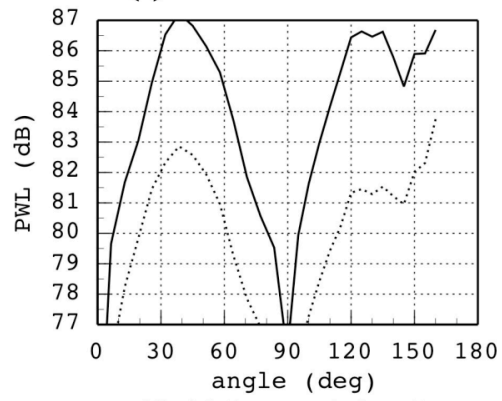

(d) 4th harmonic band

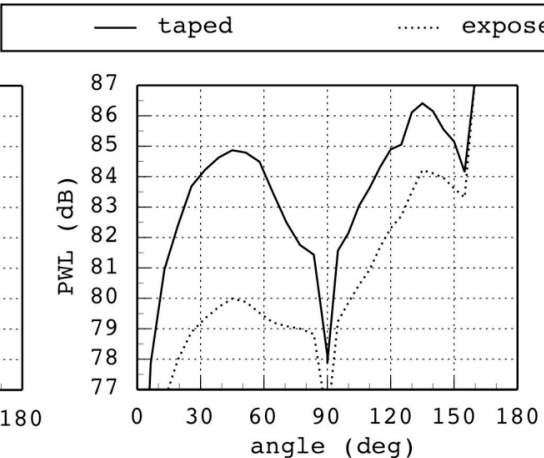

(b) 2nd harmonic band

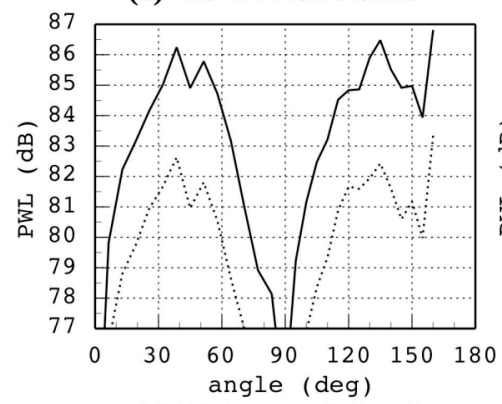

(e) 5th harmonic band

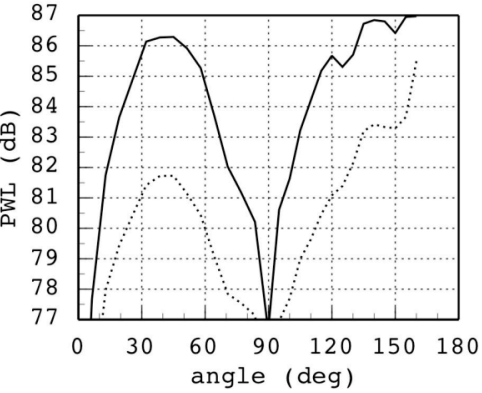

(c) 3rd harmonic band

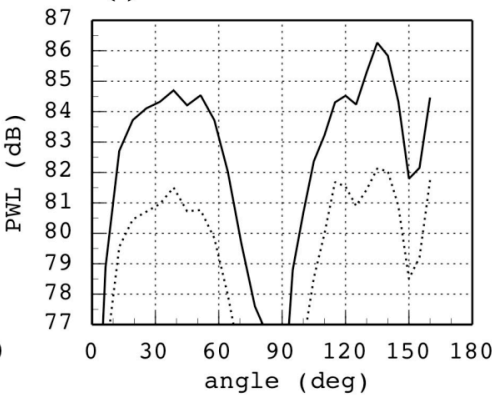

(f) 6th harmonic band

Figure 17. Farfield Directivity of FML Over-the-Rotor Compared to HW. 
Figure 18 shows the broadband attenuation in each harmonic band (relative to the hardwall configuration) obtained with FML configurations and that obtained with a traditional SDOF liner installed in the inlet duct and inner and outer walls of the exhaust duct (simultaneously). Figure 18a is the attenuation obtained from the FML in the inlet configurations (see Figure 12a); Figure $18 \mathrm{~b}$ is the attenuation obtained from the FML in the OTR configuration (see Figure 12b); and Figure 18c is the attenuation obtained from SDOF liner configuration (see Figure 12d). The FML liner provides a 9" length of treatment, while the 3 SDOF liners each provide an 18" axial length of treatment.

A comparison of Figures 18a and 18b, shows that placing the FML over the rotor results in more attenuation in the inlet arc and in aft attenuation that was not present in the inlet FML configurations. This illustrates the acoustic benefits obtained from liner placement at the source.

The attenuation obtained from the 9" long FML is equal to that obtained with a combined 54" length of SDOF liners as can be seen in the comparison between Figure 18b and 18c. This creates the potential for additional attenuation by combining liner types, or reducing weight by removing the need for inlet or exhaust duct length required for standard treatment.
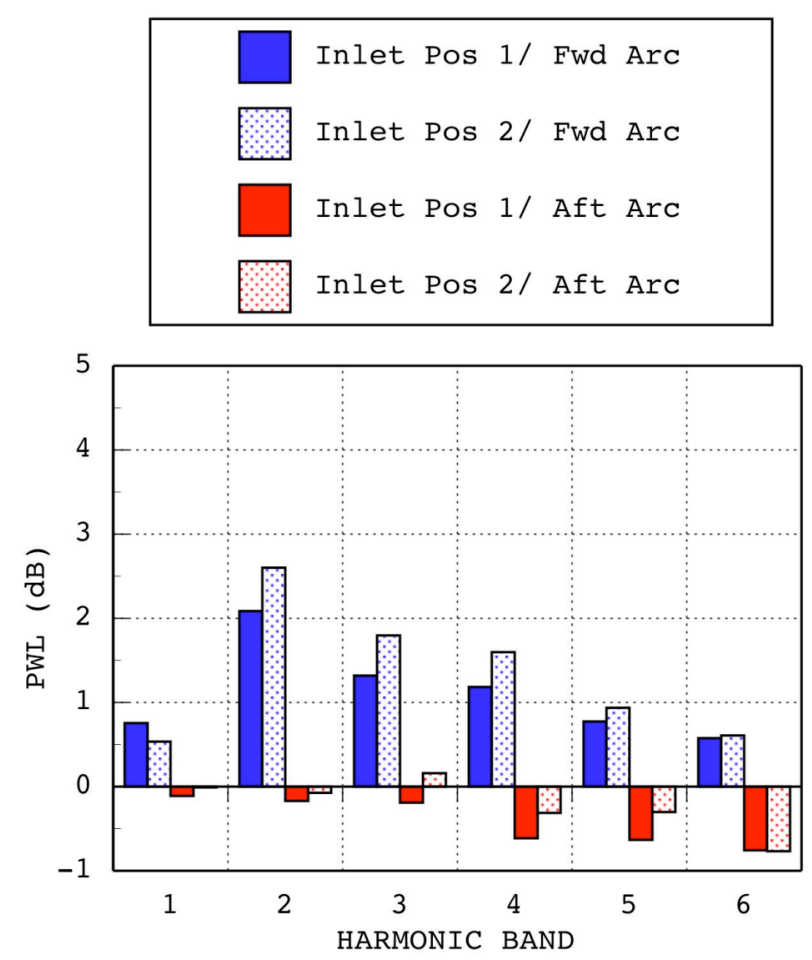

(a) FML in INLET

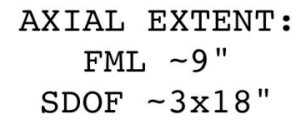

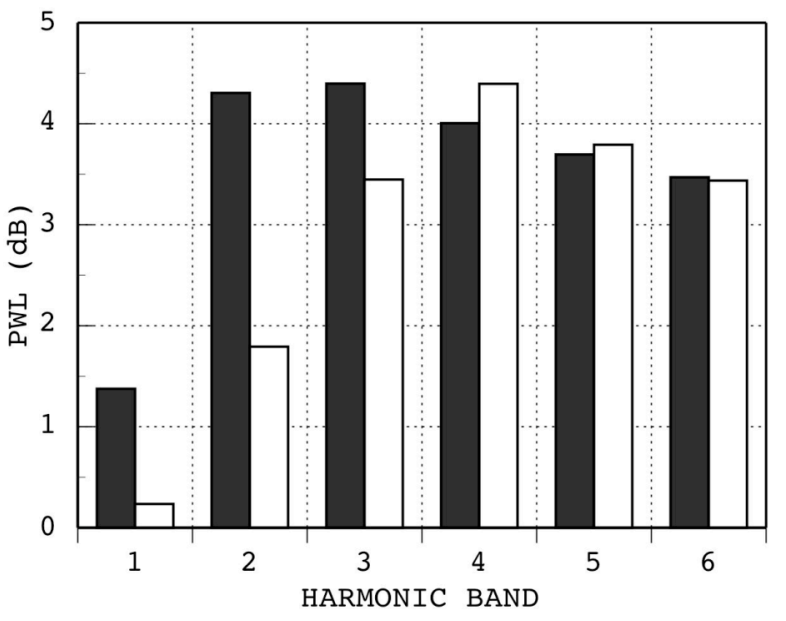

(b) FML over ROTOR
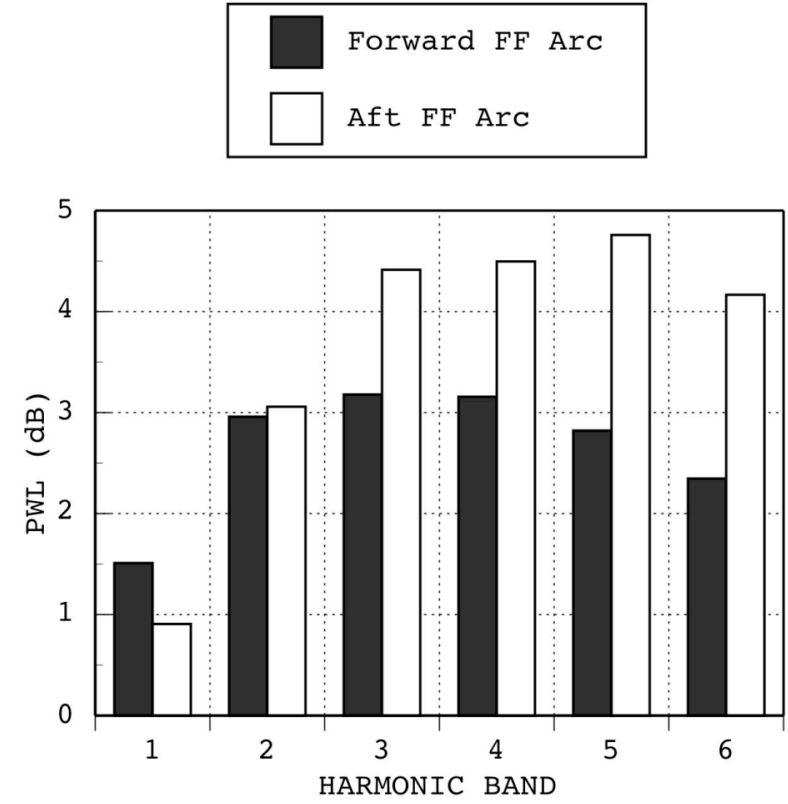

(c) SDOF in INLET/EXHAST

Figure 18. Farfield Attenuation Relative to Hardwall for FML Compared to Traditional Liners. 
To determine the efficacy of the treatment location relative to the rotor, hardwall tape was used to cover one or more of 3 physical sections of the OTR liner. Figure 19 provides the dimensions of each section of the FML that could be taped to effectively change the length of the liner. To first order, this effectively shortened the liner and/or changed its axial location relative to the projected rotor path. In reality, axial acoustic propagation occurs beneath the taped surface, but is greatly inhibited due to absorption within the foam-metal. Thus, although this is not an exact representation of such a liner change due to the axial communication path within the liner, it does provide an indication of what would be achieved if the taped portion were replaced with a completely solid axial segment.

Liner length was "adjusted" by taping surface to "convert" section to hardwall

All Taped: (TTT)

All Exposed (EEE1 \& EEE2 repeat)

Taped-Exposed-Taped (TET)

Taped-Exposed- Exposed (TEE)

Exposed -Exposed-Taped (EET)

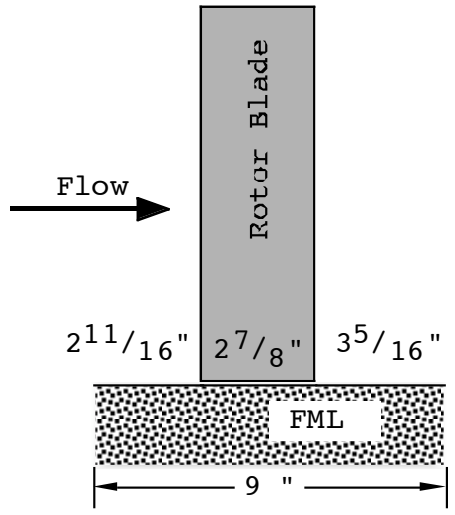

Figure 19. Close-up Schematic Showing Sections of FML

The farfield attenuation achieved in the forward or aft arcs for these alternative configurations is shown in Figure 20. Considering the forward arc (Figure 20a) the forward $2 / 3^{\text {rd }}$ of the liner achieves all of the reduction of the full liner (EET vs. EEE). Though it was not tested, by examining the attenuation achieved from the section immediately over-the rotor (TET) and noting that most of the attenuation is lost when the $1^{\text {st }}$ section of the liner (TEE) is 'removed', it is inferred that the majority of attenuation is a result of the forward $1 / 3^{\text {rd }}$ of the liner. This 'linear' analysis is not necessarily definitive in this region and this inference must be used with caution. Nonetheless, it appears that the attenuation in the forward arc is a result of the section of the liner just in front of the rotor. Further, this suggests the mechanism may be primarily acoustic attenuation rather than aerodynamic source modification.

Similar analysis of the attenuation achieved in the aft arc indicates that the majority of the attenuation achieved is a result of the section immediately over the rotor (TET). Adding the $1^{\text {st }}$ section (EET) provides an insignificant increase in attenuation; adding the $3^{\text {rd }}$, or aft, section increases the attenuation by about $1 \mathrm{~dB}$. This may support a combined acoustic attenuation/source modification mechanism.

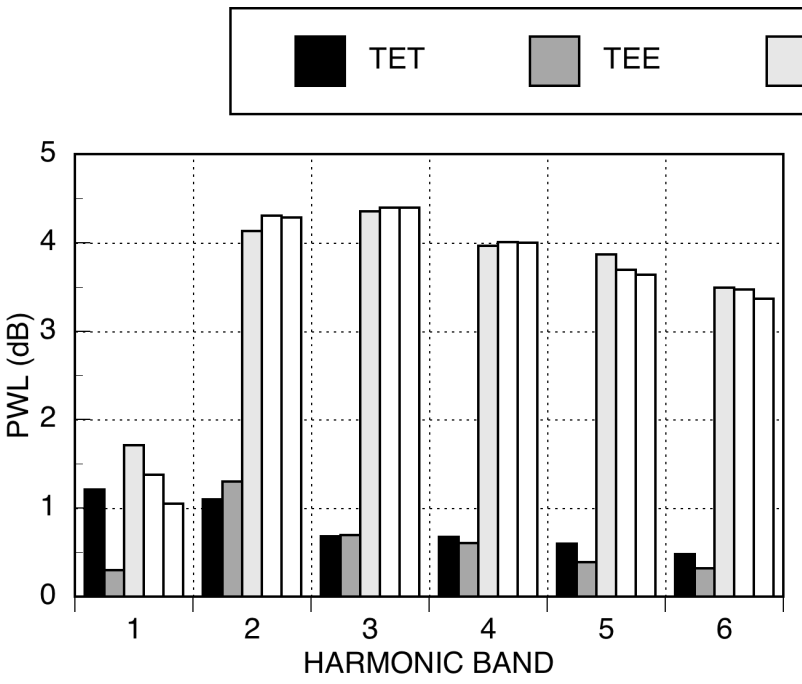

(a) Forward Arc
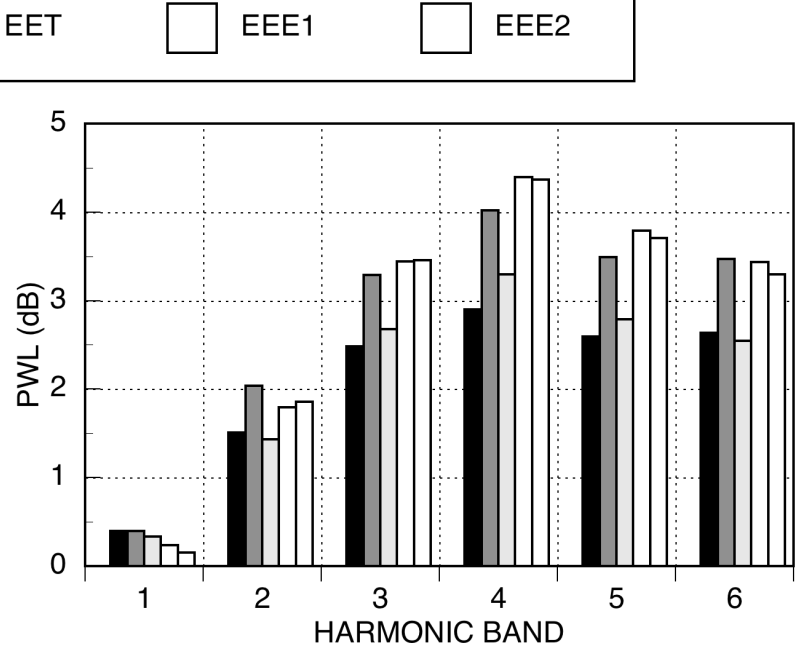

(b) Aft Arc

Figure 20. Attenuation Achieved with FML OTR sections (T)aped or (E)xposed. 
The effect of liner depth of the OTR FML was also investigated. Since the FML was built in two 1" layers (recall Figure 9b) by applying hardwall tape between the layers created by the liner segments. Thus two liner depths, 1 " and 2" were tested. Also, the prior configurations were all run with a rotor tip gap of $3 / 32^{\text {nd }}$ inch $(1.8 \%$ relative to rotor tip chord of 5.25"). The liner spool was modified to obtain a rotor clearance of $1 / 32^{\text {nd }}$ inch $(0.6 \%$ of rotor tip chord).

Figure 21 shows the attenuation achieved from these configurations relative to a hardwall baseline (again a new hardwall baseline at $1 / 32^{\text {nd }}$ inch tip gap was tested.) Decreasing the liner depth had a detrimental impact on the attenuation in the lower frequencies (harmonic bands 1-3), but increased the attenuation at the higher frequencies (harmonic bands 5-6), as might be expected from a simplistic wavelength analysis that assumes deeper liners are tuned to longer wavelength. Reducing the tip gap (with a 1" liner) had an overall positive impact on the attenuation. It may be that the tip vortex is more influenced by the smaller clearance, hence closer porous surface, implying that the greater attenuation is at least partially a result of source modification.

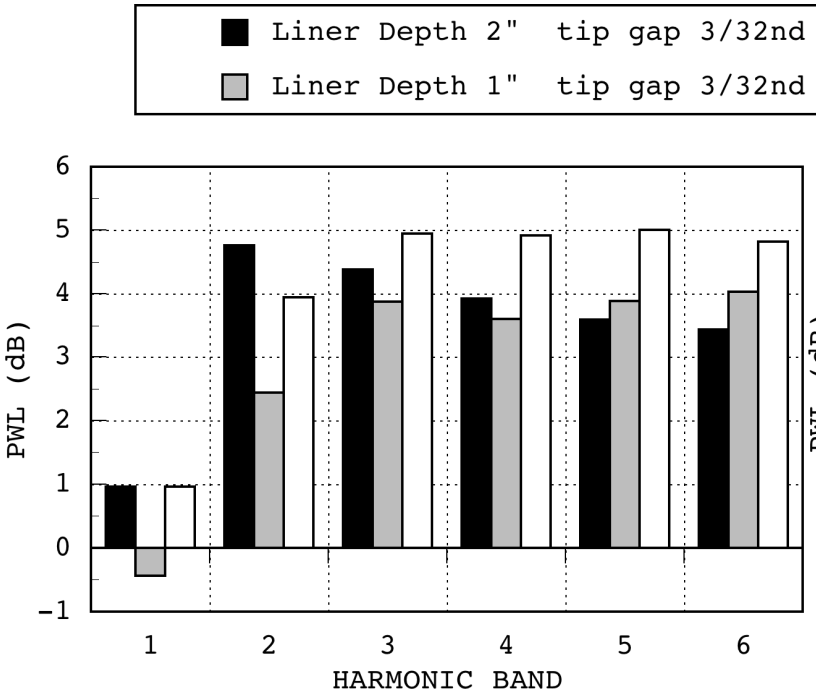

(a) Forward Arc

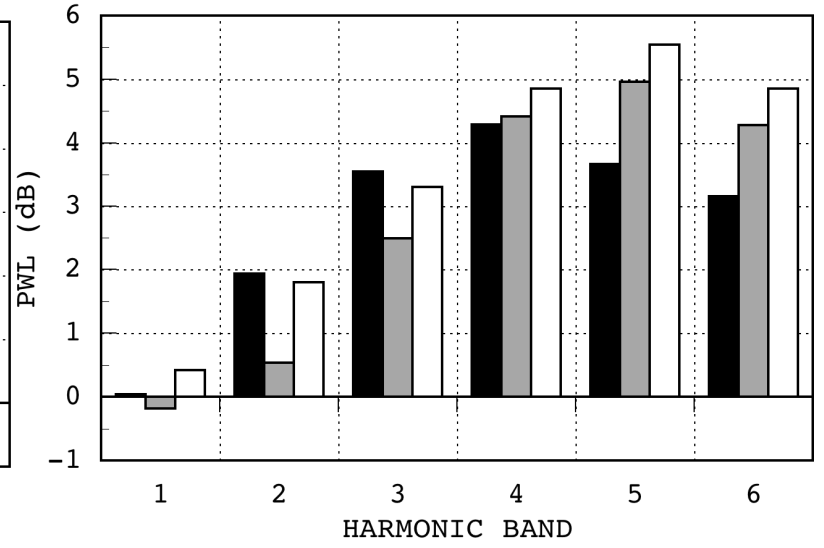

(b) Aft Arc

Figure 21. Effect of FML depth, and Rotor Tip Gap on Attenuation.

The FML spool was installed over the stators (OTS Figure 12c) to determine the effect in a non-rotating region. Figure 22 shows farfield attenuation is achieved in both arcs, with up to $3 \mathrm{db}$ more attenuation in the aft arc. Assuming that approximately the same attenuation would be achieved if the FML were placed in the aft duct, distant from the source (similar to the earlier inlet configuration - Figure 18a) the bi-directionality, and the increase in attenuation indicate the added benefit of placing an equal length of treatment over the source.

Figure 23 shows the attenuation vs. corrected speed for the original 2" liner depth with a 3/32nd tip gap. No significant effect due to RPM is observed.

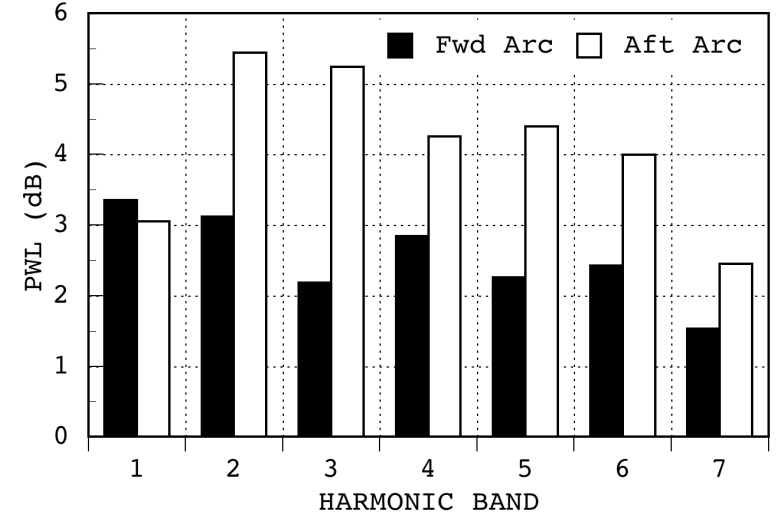

Figure 22. Attenuation of FML OTS. 


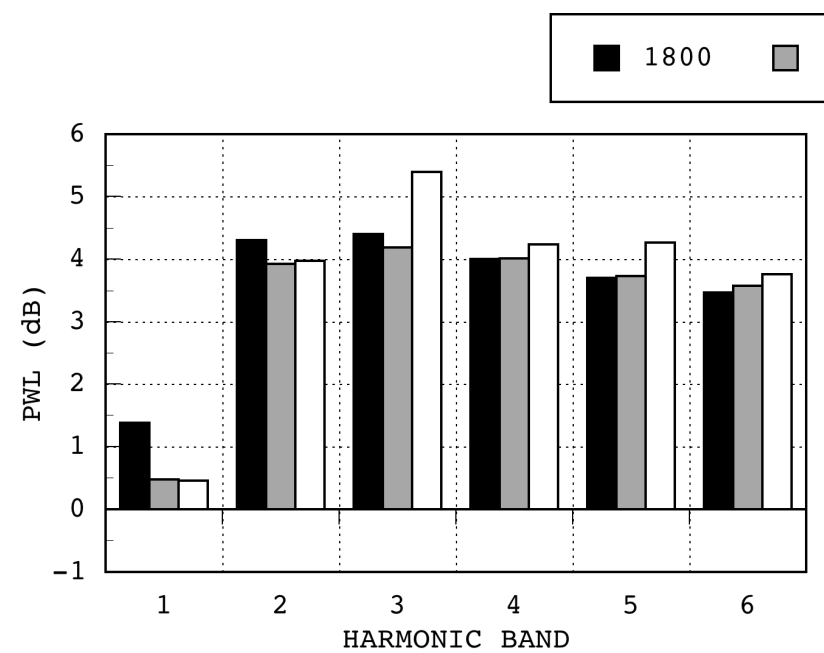

(a) Forward Farfield Arc

\section{$1600 \square 1400$}

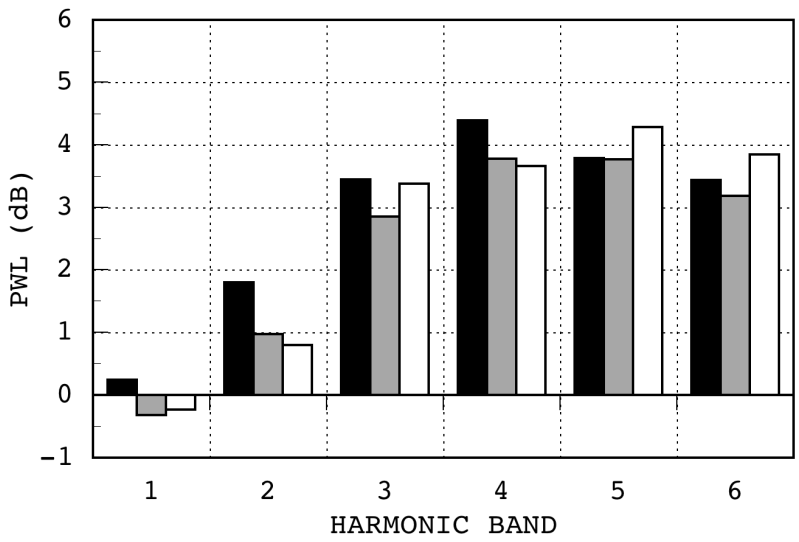

(b) Aft Farfield Arc

Figure 23. Effect of Fan Speed on FML OTR Attenuation.

\section{Wall Data}

Wall pressure taps were installed in the FML in the blade path region as shown schematically in Figure 24. A linear array of 5 taps measured the static pressure from just up-stream of the leading edge, to the trailing edge of the projected rotor path. Eighteen dynamic pressure transducers were flush mounted in three staggered linear arrays of six each, also spanning the projected path. The dynamic data were acquired with the $3 / 32^{\text {nd }}$ inch rotor tip gap; the static pressures were acquired with the $3 / 32^{\text {nd }}$ and $1 / 32^{\text {nd }}$ inch rotor tip gaps.

The time histories from the dynamic transducers for a complete revolution were time-averaged over 500 revolutions. Little change was seen in the dynamic response between hardwall and FML configurations indicating that the FML presence does not affect the viscous effects over the rotor and is therefore not shown in this paper.
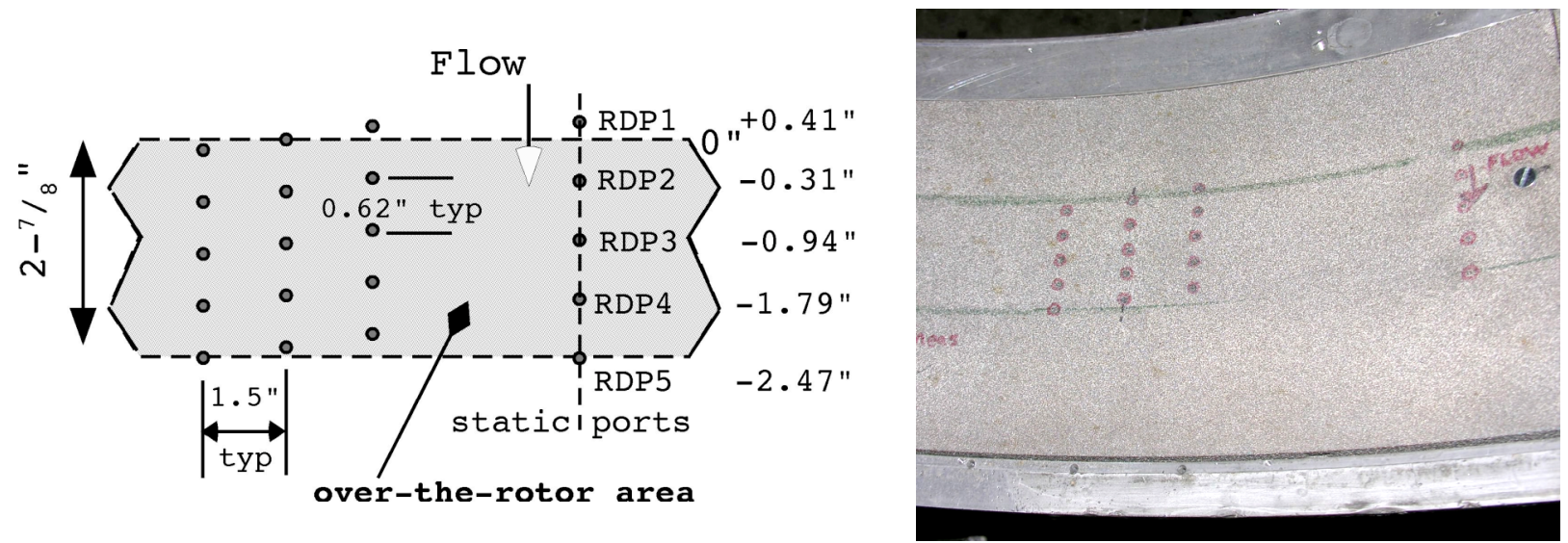

Figure 24. Locations of Static and Dynamic Pressure Measurements in FML OTR.

Wall pressures measured from the static ports are shown in Figure 25. A modification in the static wall pressure is seen due to the presence of the liner. Ahead of the leading edge (RDP1) the wall static pressure is slightly higher with the FML, indicating a decrease in duct flow. The tip pressure rise is greater for the hardwall configurations. This is probably due to leakage flow around the rotor tip relieving pressure, which reduces the tip loading. Increasing the liner depth slightly increased this effect. Reducing the tip gap also reduced the pressure. 


\section{Flow Data}

Radial traverses of total and static pressure behind the rotor were acquired. The static probe traversed 1" behind the rotor; the total pressure traversed at $3 / 4$ " and $1 \frac{1}{2}$ ". These distances are measured at the trailing edge of the rotor tip to the probe. Since the rotor untwists and the traverse remains path perpendicular to the wall, the actual distance between the rotor trailing edge and probe is reduced with immersion; the radial traverse immersion was limited as a result to prevent blade contact.

The pressures from the traverses (all relative to atmosphere) are shown in Figure 26. The liner installed over the rotor is seen to affect the pressure. A very minor difference was seen in the total pressure for a given configuration between the $3 / 4$ " and $1 \frac{1 / 2}{2}$ radial traverses, so pressure was interpolated to 1 " and plotted. The presence of the FML is seen to reduce the static and total pressures; increasing the liner depth from 1" to 2" exacerbates this effect. Again the suspected reason would be an increase in the tip flow resulting from the porous surface.

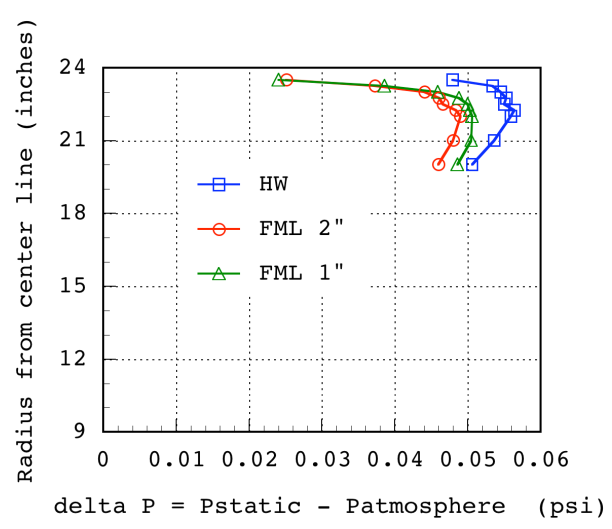

(a) Static Pressure Behind Rotor $\left(3 / 32^{\text {nd }}\right.$ rotor tip gap)

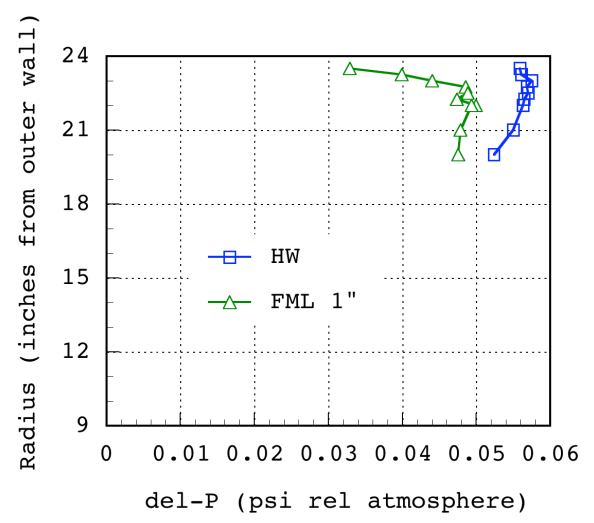

(c) Static Pressure Behind Rotor $\left(1 / 32^{\text {nd }}\right.$ rotor tip gap)

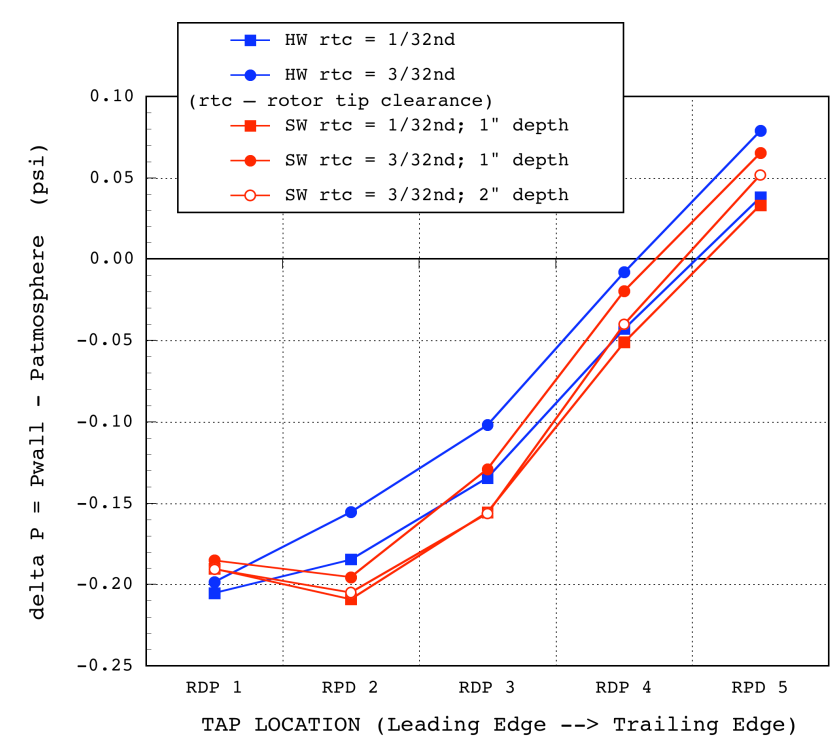

Figure 25. Static Wall Pressures Over the Rotor. (relative to atmospheric)

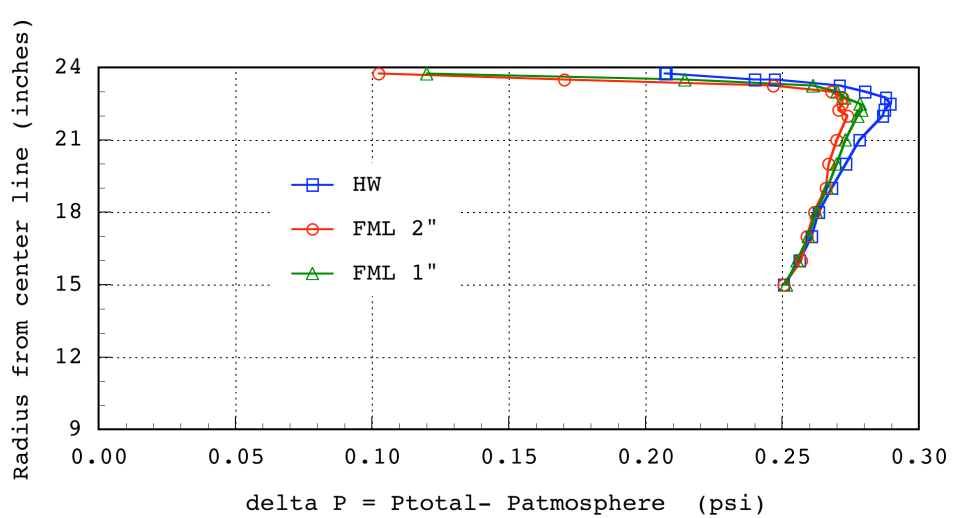

(b) Total Pressure Behind Rotor $\left(3 / 32^{\text {nd }}\right.$ rotor tip gap)

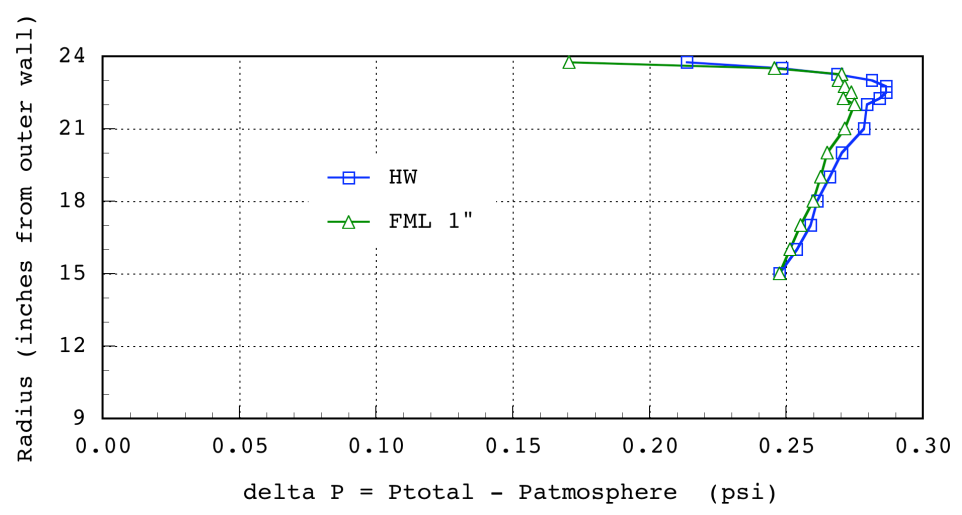

(d) Total Pressure Behind Rotor $\left(1 / 32^{\text {nd }}\right.$ rotor tip gap)

Figure 26. PiTot-Static Pressures (relative to atmosphere) Traverses Behind Rotor 
Figures 27 - 30 present two-component hot-film measurements. Radial traverses from two hot-film types, axial/circumferential and axial/radial, were acquired for each configuration at $1800 \mathrm{RPMc}$. Data at two axial locations were taken: $3 / 4$ " and $1-1 / 2$ " behind the rotor (measured as before - at the trailing edge of the rotor tip to the probe). Only the first 4 " inward from the wall at the $3 / 4$ " axial location are presented herein to focus on the tip effects. Hot-film data was time-domain averaged over 500 fan revolutions using ensembles of one blade passage width. The passage velocity at each radial location was divided by the mean velocity at that radial location, in order to bring out the circumferential variations. Figure 27 shows the axial velocity, Figure 28 the circumferential velocity, and Figure 29 the radial velocity behind the rotor. In each figure (a) is the hardwall configuration with a $3 / 32^{\text {nd }}$ rotor tip gap (b) is the hardwall configuration with a $1 / 32^{\text {nd }}$ rotor tip gap (c) is the 2 " deep FML configuration with a $3 / 32^{\text {nd }}$ rotor tip gap (d) is the 1" deep FML configuration with a $1 / 32^{\text {nd }}$ rotor tip gap. Figure 30 has the same layout except that total turbulent velocity is presented which is obtained by subtracting out the passage mean ensembles from the total velocity then calculating the rms.

The axial velocity profile shows a distinct wake and weak tip vortex from rotor in the hardwall configuration. The presence of the FML significantly intensifies the tip vortex due to its porous nature providing a path for leakage flow. The difference in the velocity due to tip gap reduction is subtle. The stronger tip vortex creates increases turbulent velocity as would be expected.

\section{Conclusion}

The acoustic characteristics of foam-metal samples were determined using a normal impedance tube. A foammetal liner was designed based on the absorption characteristics of the foam-metal and the known acoustic character of a low-speed fan. The acoustic performance of the liner was significant, especially when placed over the rotor, achieving up to $4 \mathrm{~dB}$ of broadband attenuation. The foam-metal liner effect on the flow was noted, especially affecting the pressure near the wall and increasing the size and strength of the rotor tip vortex. Due to the characteristic of the low-speed fan the impact on performance parameters such as thrust and efficiency cannot be determined using the ANCF test bed. Future testing of foam-metal liners on high-speed fans should be performed and the impact on fan performance quantified.
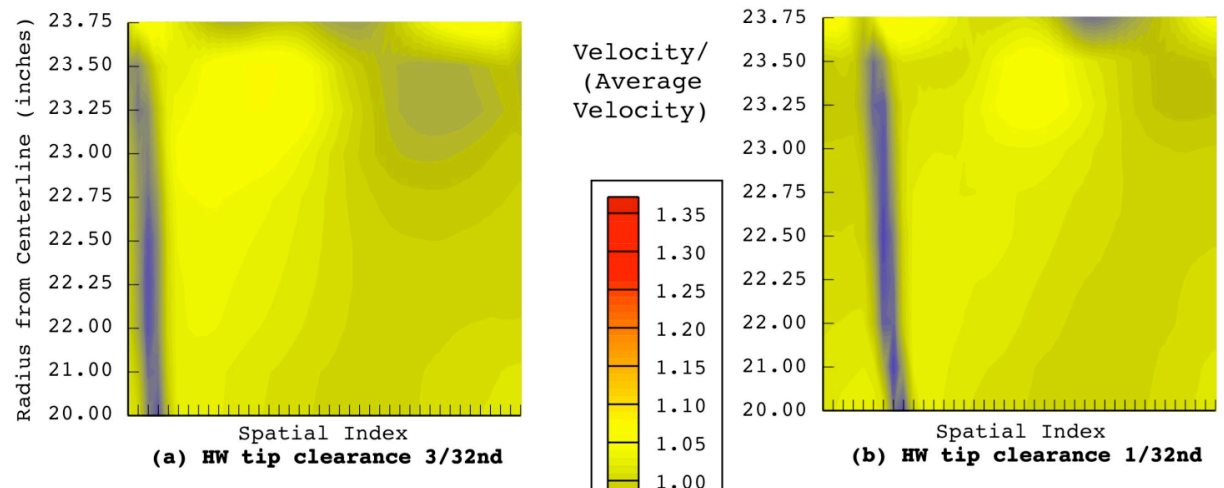

(b) HW tip clearance 1/32nd
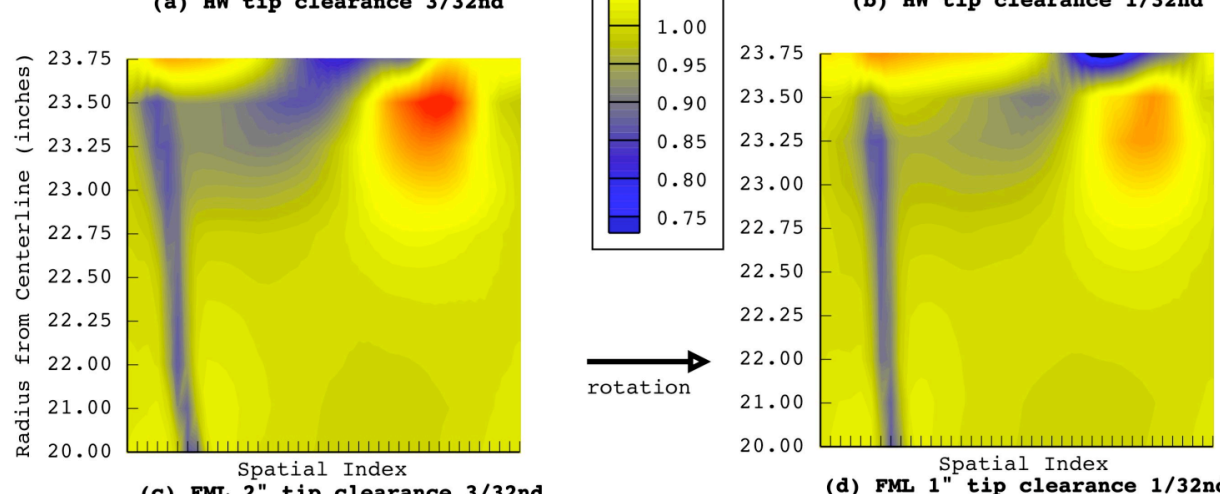

(c) FMI 2" tip clearance 3/32nd

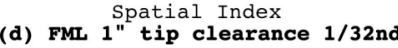

Figure 27. Magnitude of Axial Velocity Ratio Behind Rotor 


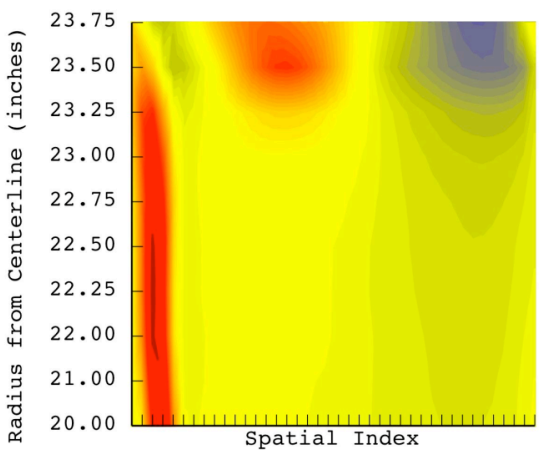

(a) HW tip clearance $3 / 32$ nd

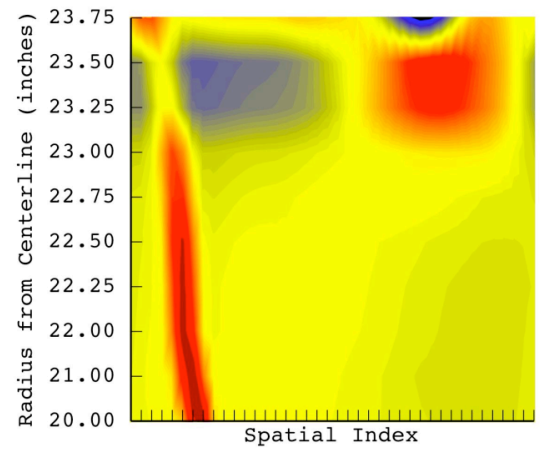

(c) FML 2" tip clearance 3/32nd

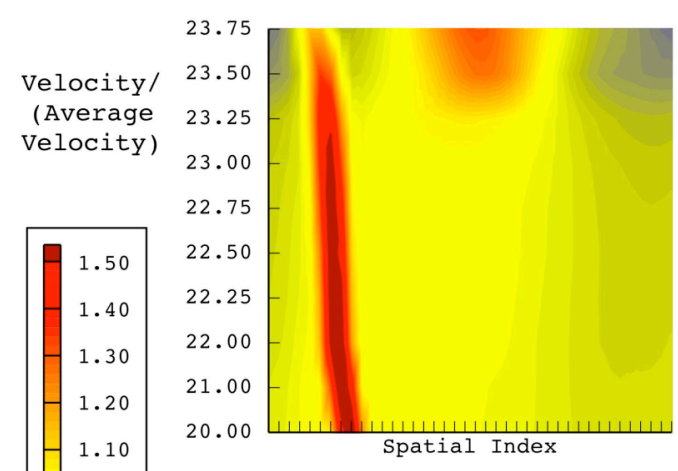

(b) HW tip clearance $1 / 32 \mathrm{nd}$

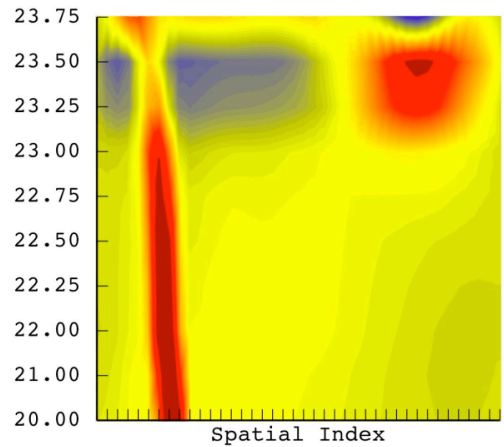

(d) FML 1" tip clearance 1/32nd

Figure 28. Magnitude of Circumferential Velocity Behind Rotor

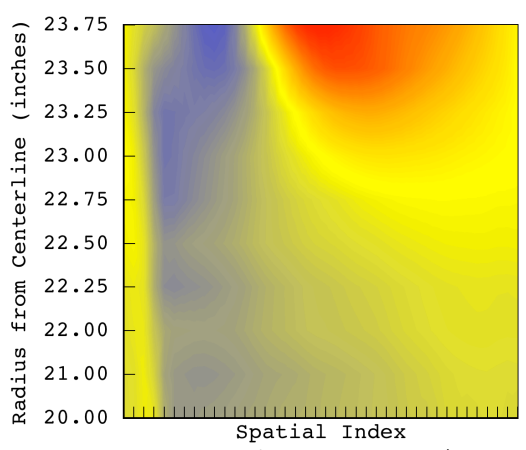

(a) HW tip clearance $3 / 32 \mathrm{nd}$

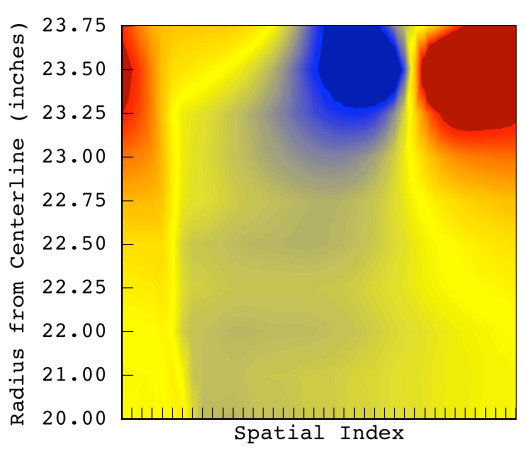

(c) FML 2" tip clearance 3/32nd

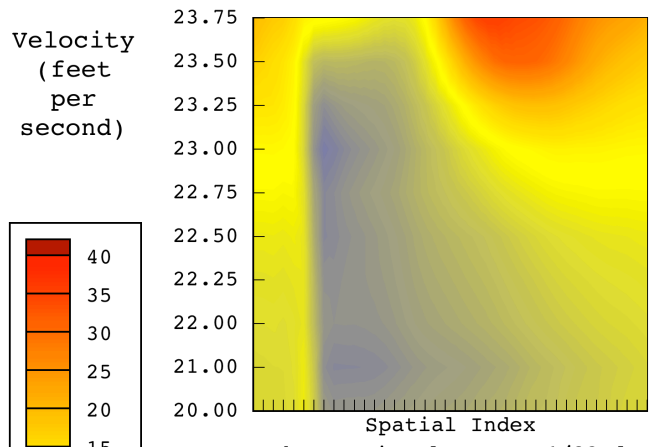

(b) HW tip clearance $1 / 32$ nd

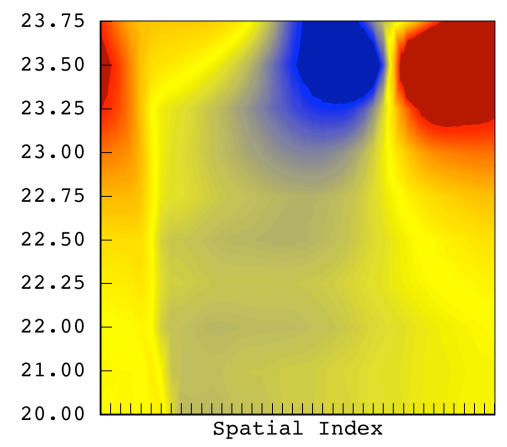

(d) FML 1" tip clearance 1/32nd

Figure 29. Magnitude of Radial Velocity Behind Rotor 


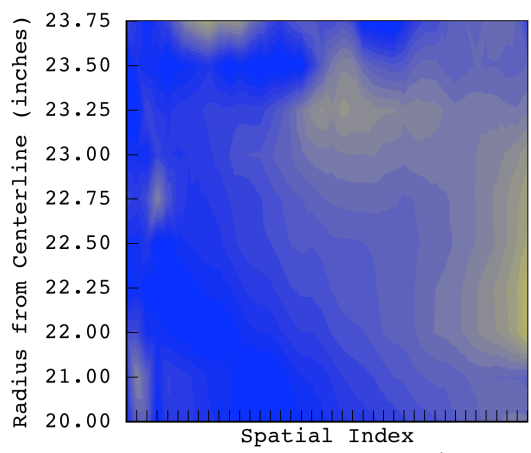

(a) HW tip clearance $3 / 32$ nd

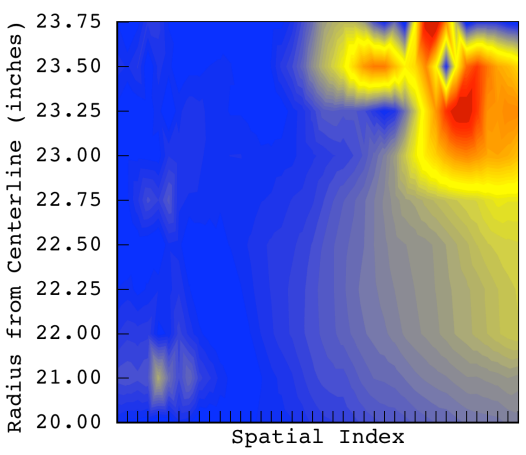

(c) FML 2" tip clearance $3 / 32 \mathrm{nd}$

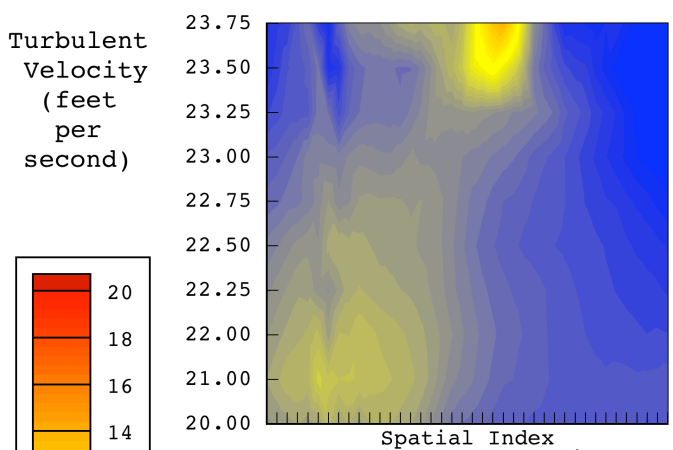

(b) HW tip clearance $1 / 32$ nd

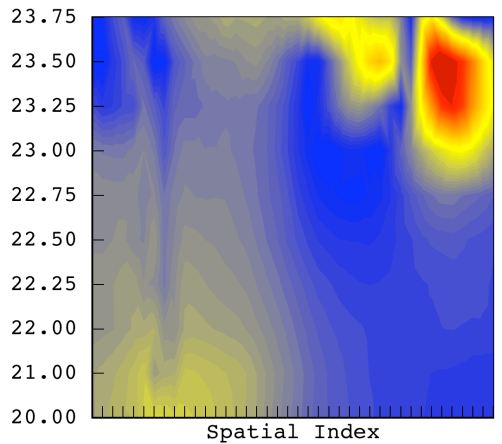

(d) FML 1" tip clearance $1 / 32$ nd

Figure 30. Turbulent Total Velocity Behind Rotor.

\section{Acknowledgments}

The authors would like to acknowledge the foundational work of Dr. Mohan Hebsur, formerly of Ohio Aerospace Institute. Dr. Hebsur encouraged this program through his experimental investigations on the foam-metal and provided the specimens for the impedance tube testing reported in this work. Also, the high-response transducer data was acquired in collaboration with GE Corporate Research and Aviation.

\section{References}

${ }^{1}$ Huff, D.L., "Noise Reduction Technologies for Turbofan Engines", Proceedings of Inter-Noise 2006, IN06 732, December 2006.

2 Smith, C.D. and Parrott, T.L., "Comparison Of Three Methods For Measuring Acoustic Properties Of Bulk Materials," Journal of Acoustical Society of America, Vol. 74, No. 5, 1983, pp. 1577-1582.

${ }^{3}$ Chung, J.Y. and Blaser, D.A., "Transfer function method of measuring in-duct acoustic properties: I. Theory," Journal of Acoustical Society of America, Vol. 68, 1980, pp. 907-921.

${ }^{4}$ Jones, M.G. and Parrott, T.L., "Evaluation of a multi-point method for determining acoustic impedance," Journal of Mechanical Systems and Signal Processing, Vol. 3, No. 1, 1989, pp. 15-35.

${ }^{5}$ Lowe, R.A., Lauer, J.T., McAllister, J., and Sutliff, D.L., "The Advanced Noise Control Fan”, AIAA-2006-3150, NASA/TM-2006-214368.

${ }^{6}$ Cooper, B.A., “A Large Hemi-Anechoic Chamber Enclosure for Community-Compatible Aeroacoustic Testing of Aircraft Propulsion Systems", Journal of the Institute of Noise Control Engineering of the USA, Jan/Feb 1994.

${ }^{7}$ Burdisso, R.A., and Ng, W.F., "Fan Noise Control Using Herschel-Quincke Resonators", NASA CR-2003-212097. AIAA 2005-3071

${ }^{8}$ De la Riva, D.H., Burdisso, R.A., and Ng, W.F., "Aft Fan Noise Control Using Herschel/Quincke-Liner Systems", 